\title{
Apostolische Auslandsreisen von Papst Franziskus, darunter Missionsreisen, in den wichtigsten nationalen Internetportalen (Jahr 2018)
}

\author{
Apostolic journeys of Pope Francis, including missionary \\ ones, in the most important national websites (2018)
}

\section{ZUSAMMENFASSUNG}

Die Kirche bediente sich in ihrer Tätigkeit und bedient sich weiterhin nicht nur der christlichen, sondern auch der säkularen

Medien. In der Geschichte waren es mit der technologischen Entwicklung:

Zeitschriften, Radio, Fernsehen und schließlich Internetmedien. Dieses letzte Medium verdrängt recht effektiv die früher genutzten Medien und wird ein Ort für

Kommunizieren von Gedanken. In den vorgenommenen Forschungen wurden die wichtigsten meinungsbildenden Portale in

Polen (www.onet.pl, www.wp.pl, www.interia. pl, www.gazeta.pl, www.o2.pl i www.fakt.pl) auf Veröffentlichung von Texten betreffend vier apostolische Auslandsreisen, darunter

Missionsreisen, von Papst Franziskus im Jahre 2018 analysiert. Es wurden die Anzahl, die Qualität, die Art und die Zeit der Veröffentlichungen untersucht sowie pastorale Schlussfolgerungen bezüglich der

Anwesenheit der Mission, der päpstlichen Pilgerfahrten sowie der ekklesischen Tätigkeit

in führenden Internet- und Laienportalen gezogen. Auf dieser Grundlage wurden folgende Forschungshypothesen beantwortet. Es scheint, die erste: „Die Medien in Polen informieren sachgemäß über die Auslandspilgerreisen von Papst
Franziskus (quantitativ und qualitativ)“ sei unbestätigt. Die zweite: „Die Vorbereitung der Geistlichen zur Benutzung neuer Medien und zur Benachrichtigung über die mit der Kirche verbundenen Fragen ist sachgemäß" ist unbestätigt; und die dritte: „Die Anzahl der Informationen und die Benachrichtigungsart über die Auslandspilgerreisen ist ungenügend" sei bestätigt.

\section{SCHLÜSSELWÖRTER:}

apostolische Reisen, Papst Franziskus, neue Medien, Internet, meinungsbildende Portale, Missionen, Kirche, Jahr 2018

\section{SUMMARY}

In its activity, the Church used and uses the media, not only defined as Christian but also as secular ones. In history, along with technological development, these were: magazines, radio, television, and finally internet media. This last medium quite effectively displaces previously used and becomes a place of communication of thoughts. The undertaken research analyzed the most important opinion forming portals in Poland (www.onet.pl, www.wp.pl, www. interia.pl, www.gazeta.pl, www.o2.pl and www.fakt.pl) in terms of publishing texts regarding four foreign apostolic journeys 
of Pope Francis, including missionary visits in 2018. The number, quality, type and time of publication were examined, and pastoral conclusions regarding the presence of missions, papal pilgrimages and ecclesial activities on secular leading websites were considered. On this basis, the following research hypotheses were

answered, it seems that the first one:

"The media in Poland properly inform about foreign pilgrimages of Pope Francis

(quantitatively and qualitatively)" - is unconfirmed. Second: "Preparation of clergy to use new media and to inform about issues related to the Church is appropriate" - is unconfirmed; and the third: "The amount of information and information on foreign pilgrimages is insufficient" - confirmed.

\section{KEYWORDS:}

apostolic journeys, pope Francis, new media, Internet, opinion leaders, mission, Catholic Church, year 2018

\title{
Zagraniczne podróże apostolskie papieża Franciszka, w tym misyjne, w najważniejszych krajowych portalach internetowych (rok 2018)
}

\begin{abstract}
ABSTRAKT
Kościół w swojej działalności posługiwał się i posługuje mediami, nie tylko tymi z definicji chrześcijańskimi, ale także świeckimi. W historii wraz z rozwojem technologicznym były to: czasopisma, radio, telewizja, aż w końcu media internetowe. To ostatnie medium dość skutecznie wypiera wcześniej używane i staje się miejscem komunikowania myśli. W podjętych badaniach poddano analizie najważniejsze portale opiniotwórcze w Polsce (www.onet.pl, www. wp.pl, www.interia.pl, www.gazeta.pl, www.o2.pl i www.fakt.pl) pod względem publikowania tekstów dotyczących czterech zagranicznych podróży apostolskich papieża Franciszka, w tym tych misyjnych, w roku 2018. Zbadano liczbę, jakość, rodzaj i czas publikacji, a także wysunięto wnioski pastoralne dotyczące obecności misji, pielgrzymek papieskich oraz działalności eklezjalnej w laickich wiodących portalach internetowych. Na tej podstawie odpowiedziano na następujące hipotezy badawcze; wydaje się, że pierwsza: „Media w Polsce właściwie informują o pielgrzymkach zagranicznych papieża Franciszka (ilościowo i jakościowo)" jest niepotwierdzona. Druga: „Przygotowanie duchownych do posługiwania się nowymi mediami i informowania o zagadnieniach związanych z Kościołem jest odpowiednie" - jest niepotwierdzona; a trzecia: „Liczba informacji i sposób informowania o zagranicznych pielgrzymkach są niewystarczające" - potwierdzona.
\end{abstract}

\section{SŁOWA KLUCZOWE:}

podróże apostolskie, papież Franciszek, nowe media, Internet, portale opiniotwórcze, misje, Kościół, 2018 r.

$S$ eit Anfang der Existenz der sozialen Kommunikationsmittel weckte das Papstamt das Interesse in Polen. Die Menschen interessierten sich, vielleicht weniger, für Neuheiten aus der Lehre der Päpste und mehr für Details aus dem Alltag des Apostolischen Stuhls, darunter für apostolische Reisen. Zweifelsohne fiel die 
Gipfelzeit dieses Interesses im Inland zwangsläufig für den Pontifikat von Johannes Paul II an. Aktueller Bischof von Rom: Jorge Mario Bergoglio SJ (geb. am 17. Dezember 1936 in Buenos Aires) - argentinischer römisch-katholischer Geistliche wurde am 13. März 2013 zum 266. Papst. Wie es schein, weckte auch der Pontifikat von Papst Franziskus Interesse der weltweiten und der polnischen sozialen Kommunikationsmittel. Insbesondere gilt es für die Frage der Flüchtlinge oder der Lehre betreffend die Ehe und die Lebensübertragung, den Ökumenismus oder den religionsübergreifenden Dialog und in der letzten Zeit betreffend das Priestertum und die Eucharistie. Die Art und Weise selbst der anschaulichen und kerygmatischen Übermittlung des Inhalts scheint nicht immer verständig zu sein, wird es jedoch sicherlich von den sowohl säkularen als auch ekklesischen Medien umfangreich übertragen und kommentiert. Es scheint, dass dieses Interesse am Anfang seines Pontifikats war, und es wächst dann, wenn der Papst von das Interesse der Medien weckende Themen spricht oder wenn er mehr Interesse weckende Bilder in seiner Übermittlung verwendet. Das Internet und insbesondere es nutzende Medien, die von Theoretikern der sozialen Kommunikationsmittel neue Medien genannt werden ${ }^{1}$, verdrängt langsam die Papierversionen der

\footnotetext{
${ }^{1}$ Neue Medien sind „Techniken, Technologien sowie Institutionen, die zur Kommunikation dienen, und die digitale Verfahren zur Erfassung, Aufzeichnung und Speicherung von Daten, zur Erstellung und Übertragung von Übermittlungen nutzen. Neue Medien zeichnen sich durch Hypertextstruktur der Übermittlung und des Empfangs, Programmierungsmöglichkeit (Asynchronie des Sendens und des Empfangs), Interaktivität, Kumulativität, globale Reichweite und gleichzeitig Individualisierung des Zugangs aus" - E. Chudziński [Red.], Słownik wiedzy o mediach, Warszawa - Bielsko-Biała 2007, S. 45. Unter den Medientheoretikern ist bezüglich der Definition die Diskussion im Gange, ob die Internetseiten und -portale auch, oder nur die sozialen Medien zu „neuen Medien“ gehören. Viele von ihnen, wie z. B. Lev Manowich, qualifiziert unter neuen Medien auch die Internetseiten und -portale. Andere - wie z. B. Paul Levinson - schlagen ihre Abtrennung als separate Mediengruppe vor. Mit der Zeit evolvierte die Einstellung von Manovich und Levinson, Magdalena Szpunar in Polen und heute spricht man eher von der Kommunikation anhand der Internetseiten, darunter der Portale sowie der sozialen Medien, und kommt man vom Termin „neue Medien“ ab. Daher ist der Begriff „neue Medien“ kein scharfer und transparenter Begriff mehr und für die Zwecke der Arbeit nennen wir sie: „Kommunikation anhand der Internetseiten sowie der sozialen Medien“ oder „Kommunikation anhand des Internets“, „Internetmedien“ und ähnlich. L. Manovich, Język nowych mediów, Warszawa 2006; derselbe, New Media From Borges to HTML, Massachusetts 2003 oder P. Levinson, Nowe nowe media, Kraków 2010. Über weitergehende Versuche ihres Definierens, die laufende Diskussion schreiben auch: M. Szpunar, Czym sq nowe mediapróba konceptualizacji, in: „Studia medioznawcze” 2008, (35) 4, S. 32; dieselbe, W stronę nowych mediów, Toruń 2010; dieselbe, Imperializm kulturowy Internetu, Kraków 2017, S. 3-134;
} 
Zeitschriften, das Radio und das Fernsehen, daher wurde es ein Ort, wo viele Veröffentlichungen über den Papst platziert werden. In diesem Gebiet erfolgt derzeit, wie es scheint, der größte Fluss von Informationen, Ideen und Gedanken. Die beliebtesten allgemeinen, publizistischen Dienste in Polen sind: www.onet.pl, www. wp.pl, www.interia.pl, www.gazeta.pl, www.se.pl und www.o2.pl. Es ist erwähnenswert, dass das Portal www.wp.pl die größte Lesergruppe hat, das ein Niveau von 17,2 Mio. Nutzer monatlich erreicht, was rund 62\% der Internetnutzer in Polen entspricht, und das Portal www.fakt.pl die kleinste (entsprechend 4,4 Mio., d. h. 20\% der Nutzer) ${ }^{2}$. Diese Portale haben somit eine riesige meinungsbildende Rolle, die die Haltung seiner Nutzer bildet, umso mehr, dass der Anteil der christlichen und katholischen Portale am Markt der Internetmedien gering ist ${ }^{3}$.

Die Kirche bemerkt die Notwendigkeit seiner Präsenz auf diesem Gebiet und ihre Lehre ist insbesondere in den Botschaften für den Tag der sozialen Kommunikationsmittel, seit 1990, mit dem Erscheinen neuer Kommunikationskanäle verbunden. Neue Informationstechnologien bilden für die Kirche Werkzeuge, die zur Erfüllung ihrer Evangelisierungsmission dienen. Theologen der sozialen Kommunikationsmittel weisen darauf hin, dass obwohl bis vor Kurzem „die Kirche Missionen führte und das Korn des Evangeliums vom Kontinent zum Kontinent übertrug, betritt sie um die Wende des 20. und 21. Jahrhunderts nach Geburt

K. Krzysztofek, Status mediów cyfrowych: stare i nowe paradygmaty, in: „Global Media Journal - Polish Edition" 2006, (1) 1, S. 14; M. Nieć, Komunikowanie społeczne i media, Warszawa 2010, S. 60-72; K. Roman, Najnowsze nowe media i stare nowe media. Spór o definicję nowych mediów, in: „Dyskurs” 2016, (22) 2, S. 20-39; T. Goban-Klas, Media i komunikowanie masowe. Teorie i analizy prasy, radia, telewizji i Internetu, Warszawa 1999; I. Hofman, Paradygmaty nowej dyscypliny, in: „Studia Medioznawcze” 2019, (79) 4, S. 308-317.

${ }^{2}$ Siehe: Laut der Forschungen gehören zu den meinungsbildenden Portalen, die das Lesen auf dem Niveau von ca. 6 Mio. Nutzer in Polen erreichen: www.wp.pl (17,2 Mio. Nutzer, 62\% Bereich im Internet), www.onet.pl (17,0 Mio., 61,0\%), www.interia.pl (13,4 Mio., 48,3\%), www.gazeta.pl (11,0 Mio., 40,0\%), www.se.pl (8,30 Mio., 30,0\%), www.o2.pl (8,30 Mio., 30,0\%) und www.fakt.pl (4,4 Mio., 20,2\%). Quelle: Megapanel PBI/Gemius, Dezember 2019, Anzahl der Versuchspersonen: N=204 618, mit der Forschung umfasste Gruppe: 7-75 Jahre.

${ }^{3}$ Siehe: Laut dieser Forschungen waren die am häufigsten besuchten christlichen Webseiten: www.deon.pl (0,71 Mio. Nutzer, 2,53\%), www.gosc.pl (0,71 Mio., 2,50\%), www.opoka.org.pl (0,57 Mio., 2,05\%), www.aleteia.org (0,55 Mio., 1,95\%), www.wiara.pl (0,47 Mio., 1,67\%), www.misyjne.pl (0,46 Mio., 1,62\%), www.niedziela.pl (0,45 Mio., 1,60\%). Quelle: Megapanel PBI/Gemius, November 2019, Anzahl der Versuchspersonen: N=145 266, mit der Forschung umfasste Gruppe: 7-75 Jahre. 
Christi einen ganz „neuen Boden ${ }^{4 “}$. Der erste Papst, der die besondere Bedeutung des Internets bemerkte, war Johannes Paul II. In der Botschaft zum Welttag der Massenmedien sprach er über eine „Ära der Computer" und die Verwendung von „computerisierten Beteiligungssystemen“, d. h. Internet, für die Umsetzung der Kirchenmission. ${ }^{5}$. Papst Benedikt XVI. nennt das Internet ein „digitales Kontinent, das zu evangelisieren ist, das jedoch auch evangelisiert ${ }^{6 \text { ", }}$ und Papst Franziskus stellt die Internetmedien als praktische Werkzeuge dar, die an der Kommunikation der Barmherzigkeit teilnehmen können ${ }^{7}$ und weist auch auf damit verbundene Probleme, insbesondere die Fake News oder Deepfakes hin ${ }^{8}$. Sofern die christlichen Internetportale umfangreich über die ekklesische Tätigkeit informieren und sie analysieren, wurden jedoch noch keine breiteren Forschungen der Kirchenanwesenheit im Laienbereich des Internets vorgenommen. Diese Forschung betrifft einen Abschnitt dieser Präsenz in den am meisten besuchten meinungsbildenden Portalen im Inland, die Gegenstand einer ausgefeilten Schlussfolgerung sein sollte. Es betrifft Papst Franziskus und seine apostolischen Reisen im Jahre 2018. Die vorigen Jahre des Pontifikats wurden in den früheren Forschungen analysiert ${ }^{9}$.

${ }^{4}$ J. Kloch, Kościół w Polsce wobec Web 2.0, Kielce 2013, S. 21.

${ }^{5}$ Siehe Johannes Paul II., Orędzie na 24. Światowy Dzień Środków Społecznego Przekazu, Misja Kościoła w erze komputerów, 24. Januar 1990.

${ }^{6}$ Siehe Benedikt XVI., Orędzie na 43. Światowy Dzień Środków Społecznego Przekazu. Nowe technologie, nowe relacje. Trzeba rozpowszechniać kulturę szacunku, dialogu i przyjaźni, 24. Januar 2009.

${ }^{7}$ Siehe Franziskus, Orędzie na 50. Światowy Dzień Środków Społecznego Przekazu Komunikacja i Miłosierdzie - owocne spotkanie, 24. Januar 2016.

${ }^{8}$ Siehe Franziskus, Orędzie na 52. Światowy Dzień Środków Społecznego Przekazu «Prawda was wyzwoli» (J 8, 32). Fake news a dziennikarstwo pokoju“ 24. Januar 2018; Derselbe, Orędzie na 54. Światowy Dzień Środków Społecznego Przekazu "Abyś opowiadał dzieciom Twoim i wnukom» (Wj 10, 2). Życie tworzy historię", 24. Januar 2020.

${ }^{9}$ Siehe M. Wrzos, Zagraniczne podróże apostolskie, $w$ tym misyjne, papieża Franciszka w najważniejszych krajowych portalach internetowych, cz. I (lata 2013-2014), in: „KulturaMedia-Teologia”, 1 (28) 2017, S. 111-141; Derselbe, Zagraniczne podróże apostolskie, w tym misyjne, papieża Franciszka $w$ najważniejszych krajowych portalach internetowych, cz. II (rok 2015); in: „Kultura-Media-Teologia”, 4 (31) 2017, S. 140-179; Derselbe, Apostolische Auslandsreisen von Papst Franziskus, darunter Missionsreisen, in den wichtigsten nationalen Internetportalen (Jahr 2016), in: „Kultura-Media-Teologia”, 2 (38) 2019, S. 67-114; Derselbe, Apostolische Auslandsreisen von Papst Franziskus, darunter Missionsreisen, in den wichtigsten nationalen Internetportalen (Jahr 2017), in: „Kultura-Media-Teologia”, 4 (39) 2019, S. 159-198. Unter den gesamtpolnischen Medien wird das zu analysierende Portal www.fakt.pl anstatt www.se.pl \#, obwohl das letzte mehr Nutzer hat, aufgrund der Fortsetzung der Forschungen sein. 
Der Forschungsprozess besteht aus zwei Stufen: Die erste ist die Bearbeitung der im Internet veröffentlichten Artikeln mit der Methode einer quantitativ-qualitativen Analyse des Inhalts. Dann nehmen wir eine theologisch-missionswissenschaftliche Analyse der erhaltenen Daten vor und ziehen pastorale Schlussfolgerungen. Die Forschungsarbeiten teilen wir in Folgendes:

1. Inhaltsanalyse der Artikeln über die Reisen, darunter Missionsreisen von Papst Franziskus (2018) in den wichtigsten Portalen im Inland mit der quantitativ-qualitativen Methode. Die gesammelten Artikeln betreffen die folgenden Pilgerreisen:
a. 15.-21. Januar - Chile, Peru;
b. 21. Juni - die Schweiz;
c. 25.-26. August - Irland;
d. 22.-25. September - Litauen, Lettland, Estland;

\section{Theologen der sozialen Kommunikationsmittel weisen darauf hin, dass obwohl bis vor Kurzem „die Kirche Missionen führte und das Korn des Evangeliums vom Kontinent zum Kontinent übertrug, betritt sie um die Wende des 20. und 21. Jahrhunderts nach Geburt Christi einen ganz „neuen Boden“.}

2. theologische Analyse der veröffentlichten Inhalte;

3. pastorale Schlussfolgerungen und Antwort auf die Forschungshypothesen, a.) Die Medien in Polen informieren sachgemäß über die Auslandspilgerreisen von Papst Franziskus (quantitativ und qualitativ); b.) Die Vorbereitung der Geistlichen zur Benutzung neuer Medien und zur Benachrichtigung über die mit der Kirche verbundenen Fragen ist sachgemäß; c.) Die Anzahl der Informationen und die Benachrichtigungsart über die Auslandspilgerreisen ist ungenügend. 


\section{INHALTSANALYSE DER IN DEN WICHTIGSTEN PORTALEN VERÖFFENTLICHTEN ARTIKELN ÜBER DIE MISSIONSREISEN VON PAPST FRANZISKUS (2018) MIT DER QUANTITATIV-QUALITATIVEN METHODE}

\begin{tabular}{|c|c|}
\hline \multicolumn{2}{|c|}{ Methodologie der ersten Stufe der Forschungen } \\
\hline - Analysierte Zeit: & $\begin{array}{l}\text { a. 15. Oktober } 2017 \text { - 21. April 2018; } \\
\text { b. 21. März } 2018 \text { - 21. September 2018; } \\
\text { c. 25. Mai } 2018 \text { - 26. November 2018; } \\
\text { d. 22. Juni } 2018 \text { - 25. Dezember 2018; } \\
\text { Drei Monate vor und drei Monate nach den päpstlichen Pilgerreisen; }\end{array}$ \\
\hline - Analysierte Dienste: & $\begin{array}{l}\text { www.onet.pl; www.wp.pl; www.interia.pl; www.gazeta.pl; www. } \\
\text { o2.pl und www.fakt.pl; }\end{array}$ \\
\hline - Inhaltsquellen: & Newspoint \\
\hline - Tiefe der Analyse: & $\begin{array}{l}\text { verbunden (automatisch und manuell) - in den erhaltenen Ergebnissen } \\
\text { der automatischen Suche nach den programmierten Algorithmen erfolgt } \\
\text { Selektion der Wahlrichtigkeit durch den Forscher. }\end{array}$ \\
\hline - Sprache der Quellen: & Polnisch \\
\hline - Sprache der Suche: & Polnisch \\
\hline $\begin{array}{l}\text { - Filtern von Spam/ } \\
\text { Boot-Dateien: }\end{array}$ & $\begin{array}{l}\text { verbunden (automatisch und manuell) - in den erhaltenen Ergebnissen } \\
\text { der automatischen Suche nach den programmierten Algorithmen erfolgt } \\
\text { Selektion der Wahlrichtigkeit durch den Forscher; }\end{array}$ \\
\hline $\begin{array}{l}\text { - Schlüsselfragen/-wör- } \\
\text { ter: }\end{array}$ & 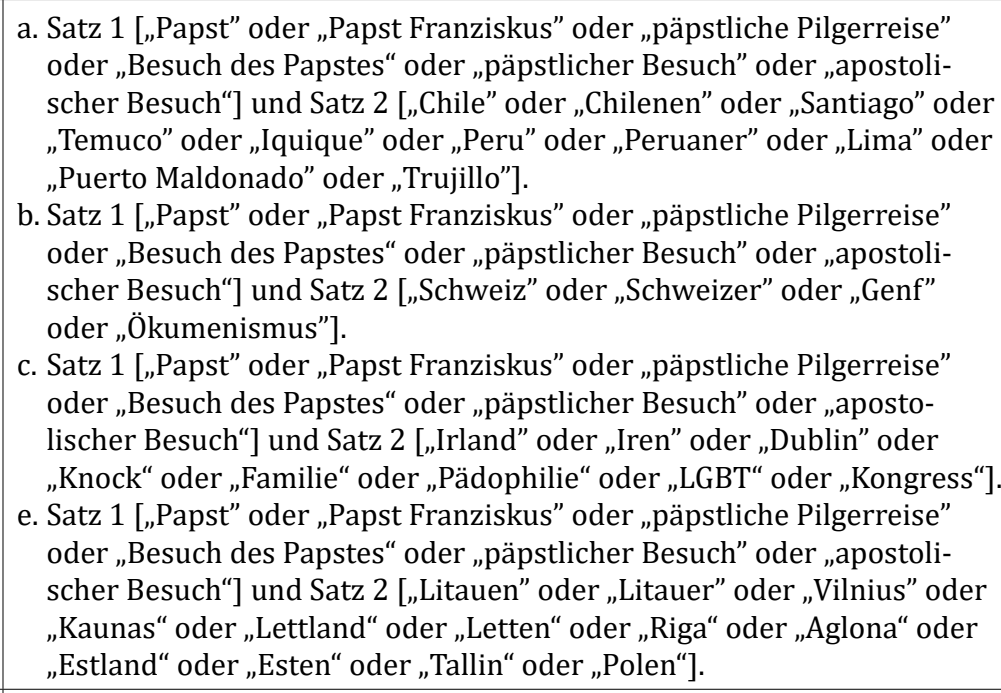 \\
\hline - Analyseeinheit: & $\begin{array}{l}\text { beliebiges Wort aus Satz } 1 \text { zzg. beliebiges Wort als Satz 2, in beliebiger } \\
\text { Sprachversion; }\end{array}$ \\
\hline - Auswertung: & $\begin{array}{l}\text { verbunden (automatisch und manuell) - in den erhaltenen Ergebnissen } \\
\text { der automatischen Suche nach den programmierten Algorithmen (positiv, } \\
\text { neutral, negativ) erfolgt Selektion der Wahlrichtigkeit durch den Forscher; }\end{array}$ \\
\hline
\end{tabular}




\begin{tabular}{l|l} 
- Anzahl der analysierten & a. $70 ;$ \\
Artikeln: & b. $10 ;$ \\
& c. $40 ;$ \\
& d. $54 ; \Sigma=174$.
\end{tabular}

\subsection{5.-21. Januar - Chile, Peru}

Die apostolische Reise von Papst Franziskus nach Chile und Peru fand vom 15. bis zum 21. Januar 2018 statt und es war der 22. päpstliche Besuch. Die Reise nach Chile verlief nach dem Motto: „Meinen Frieden gebe ich euch“ und nach Peru „Geeint in der Hoffnung“. In Chile besuchte der Papst Santiago de Chile, Temuco und Iquique, und in Peru Lima, Puerto Maldonado und Trujillo. Franziskus war der zweite Papst, der Chile und Peru besuchte. Vor ihm besuchte Chile Johannes Paul II vom 1. bis zum 6. April 1987, hingegen besuchte er Peru zweimal: 1.-5. Februar 1985 sowie 14.-16. Mai 1988.

In den analysierten Portalen wurden 70 Texte zu diesem Thema veröffentlicht. Der erste waren die Agenturnachrichten vom 10. Januar 2018 im Portal www.onet.pl. Sie betrafen sexuelle Missbräuche gegenüber Minderjährigen in

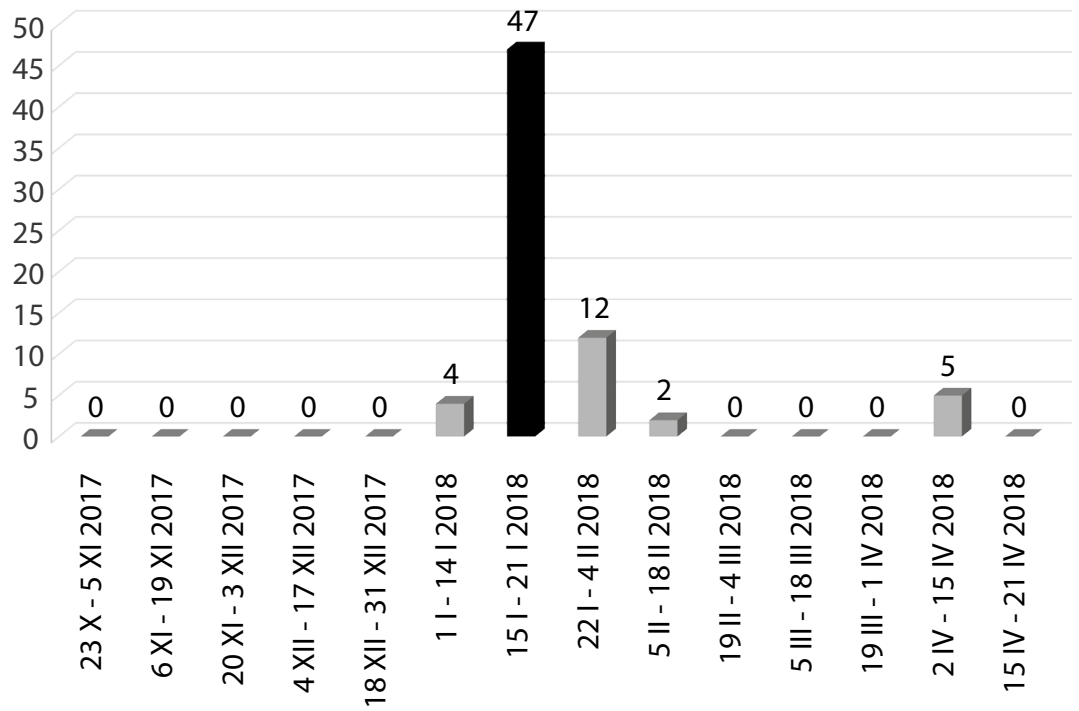

Diagramm Nr. 1. Anzahl der Publikationen zum Thema des Besuchs von Papst Franziskus in Chile und Peru in den polnischen Portalen nach dem Veröffentlichungstag, $\mathrm{N}=70$

Quelle: Newspoint 
einem der katholischen Vereine. Das Problem wurde im Zusammenhang mit der schnellen Reaktion des Apostolischen Stuhls aufgrund der näher kommenden Reise von Papst Franziskus dargestellt. Die Information wurde durch die Redaktion doppelt gemacht. Die letzte Publikation erschien am 13. April 2018, auch im Portal www.onet.pl und betraf die Notwendigkeit des Rücktritts des Episkopats von Chile im Zusammenhang mit den Missbräuchen in der Kirche und mit der Reaktion auf die Vorwürfe gegen Bischöfe des Papstes nach der Pilgerreise nach diesem Land. Die direkt mit der Pilgerreise verbundenen Berichte wurden während ihrer Dauer veröffentlicht. Es waren am häufigsten Pressemitteilungen bzw. ihre Kommentare (59). Es gab 4 veröffentlichte Nachrichten in der Zeit vor der päpstlichen apostolischen Reise und 19 danach. Die letzten davon wurde drei Monate nach ihrer Beendigung veröffentlicht und waren mit dem Episkopat von Chile verbunden.

Die meisten Nachrichten zum Thema der päpstlichen Pilgerreise nach Chile und Peru veröffentlichte das Portal www.onet.pl (23), was ihm rund 33\% des
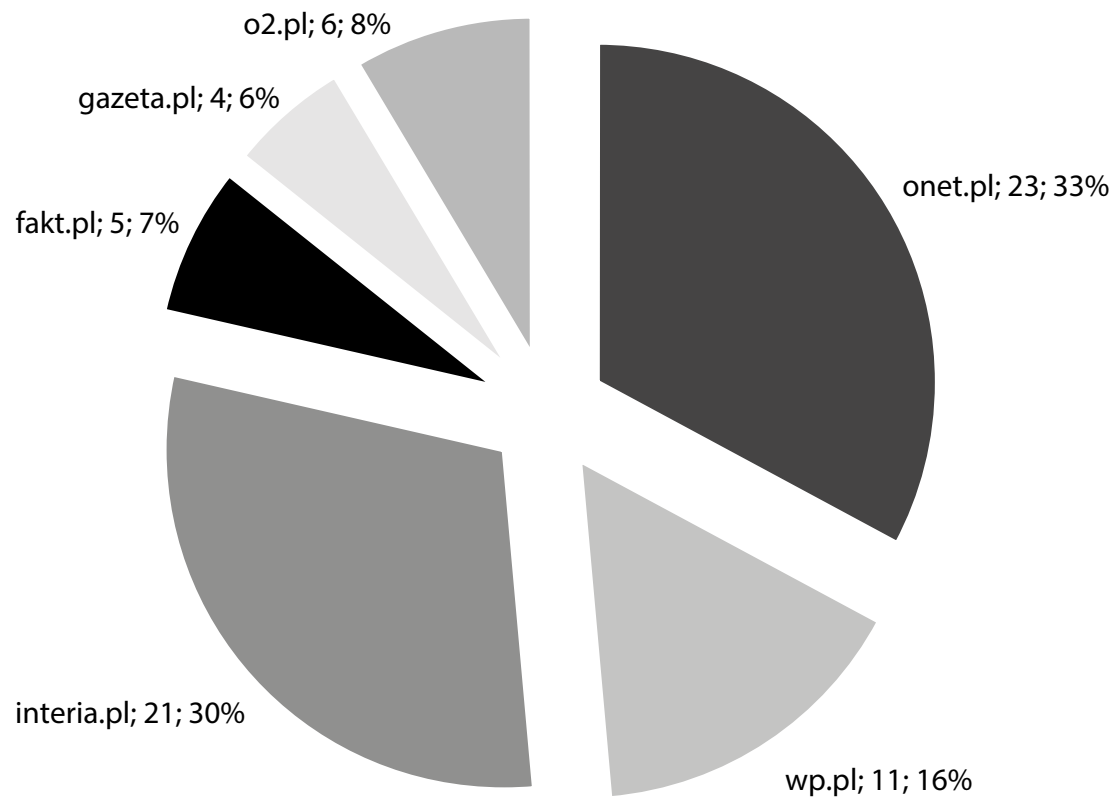

Diagramm Nr. 2. Anzahl der Publikationen zum Thema des Besuchs von Papst Franziskus in Chile und Peru in den polnischen Portalen nach dem Veröffentlichungsort, $\mathrm{N}=70$

Quelle: Newspoint 
Anteils am Markt der Internetnachrichten zu diesem Thema ausmacht. Die weiteren Portale unter Berücksichtigung der Publikationsanzahl waren entsprechend: www.interia.pl (21), www.wp.pl (11), www.o2.pl (6), www.fakt.pl (5), und am wenigsten veröffentlichte das Portal www.gazeta.pl (4). Im Falle des Portals www.gazeta.pl erschienen einzelne Nachrichten während der Pilgerreise. Derzeit sind sie nicht mehr im Portal verfügbar.

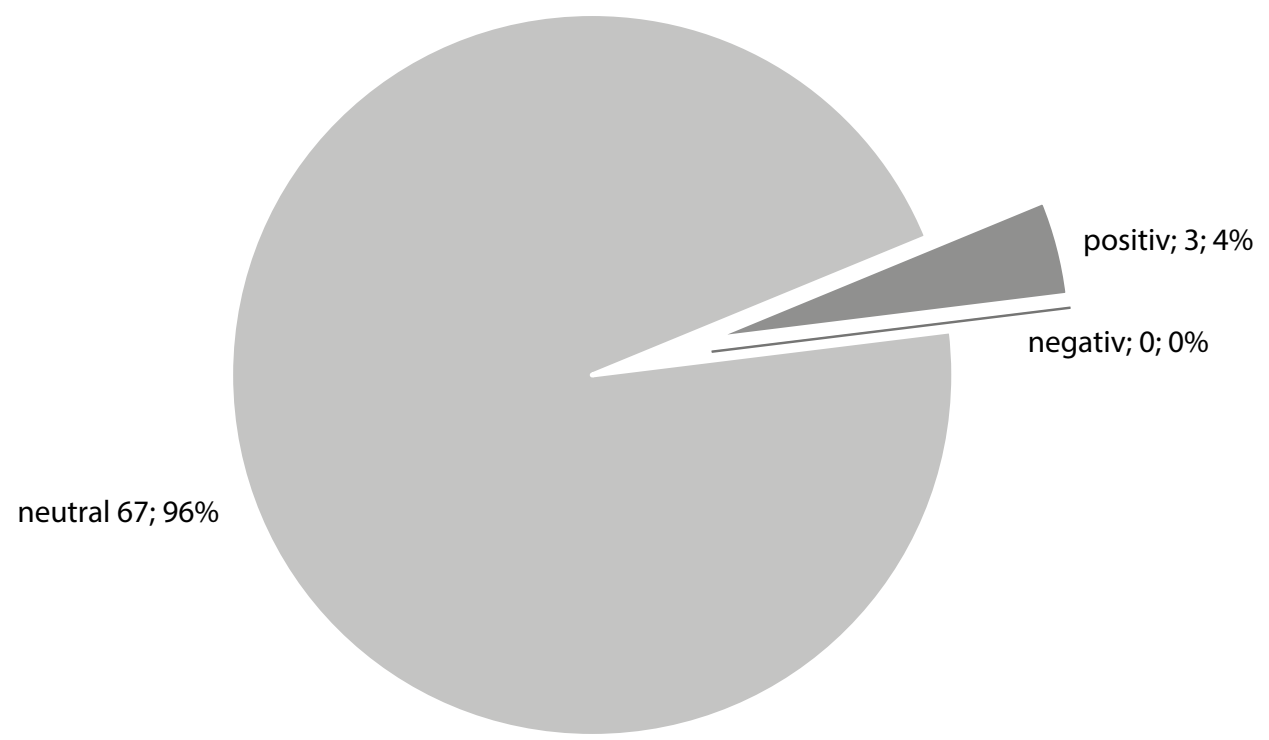

Diagramm Nr. 3. Anzahl der Publikationen zum Thema des Besuchs von Papst Franziskus in Chile und Peru in den polnischen Portalen nach der Veröffentlichungsart, N=70 Quelle: Newspoint

Weitere Stufe der auszuführenden Forschungen war Ermittlung der Kommunikationsweise über diese apostolische Pilgerreise von Papst Franziskus. Aus den durchgeführten Forschungen geht es hervor, dass von 70 der veröffentlichten Nachrichten positiv (3) bzw. neutral waren (67). Negative Informationen, auch über sexuelle Missbräuche, die die Kirche eindeutig herabmindern würden, gab es nicht. Die Autoren zeigten damals die Gegenwirkung von Papst Franziskus. Es hängt unter anderem damit zusammen, dass es sich bei den meisten Publikationen um Agenturmitteilungen von Informationsnatur handelt. 
Das Zahlenverhältnis der positiven und negativen zum Thema der besprochenen Pilgerreise im gegeben analysierten Medium veröffentlichten Nachrichten ist aufgrund dessen, dass es lediglich neutrale Nachrichten waren, identisch.

Die meisten geforschten Internetportale bedienen sich der Mitteilungen der Polnischen Nachrichtenagentur (PAP), der Katholischen Informationsagentur (KAI), der Rundfunkinformationsagentur (RAI) und von Radio Vatikan (RV).

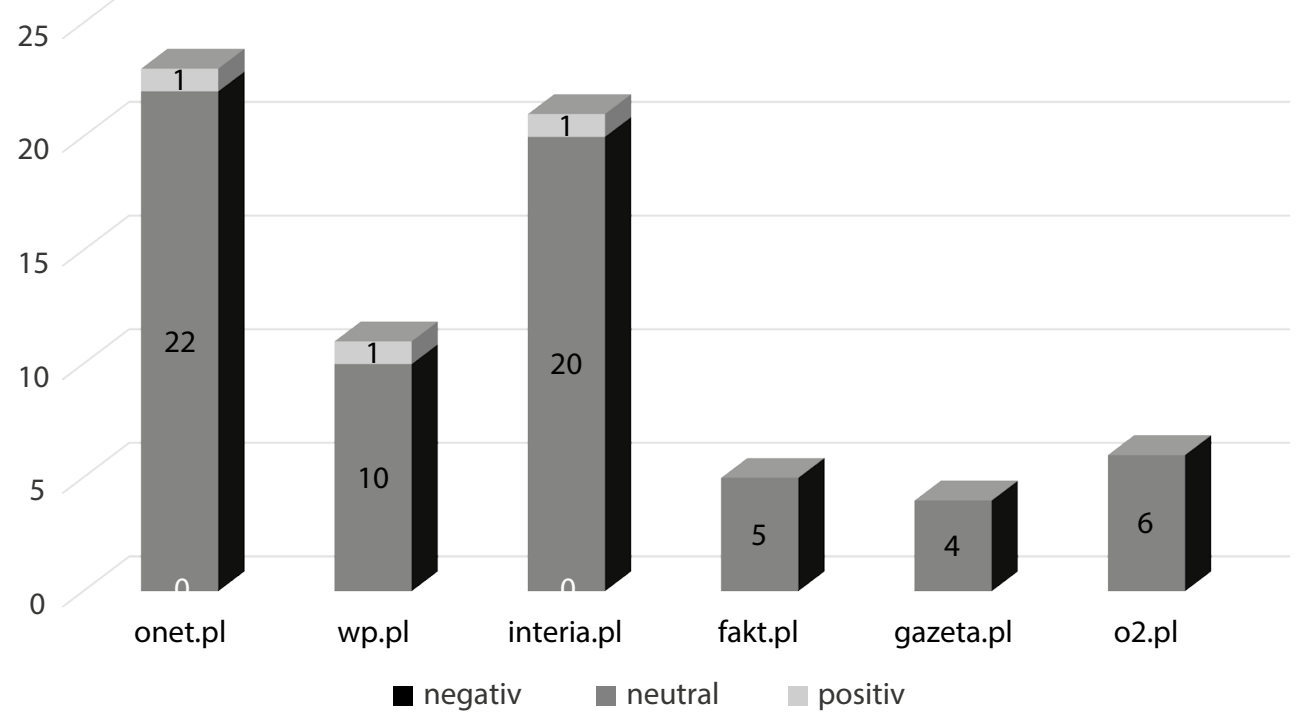

Diagramm Nr. 4. Anzahl der Publikationen zum Thema des Besuchs von Papst Franziskus in Chile und Peru in den polnischen Portalen nach dem Veröffentlichungsort und -art, $\mathrm{N}=70$ Quelle: Newspoint

Die Aussage der Nachrichten war somit neutral. Es gab keine negativen. Materialien, die die Aussage und den Inhalt der päpstlichen Reden vertieften, wurden grundsätzlich nicht veröffentlicht und man konzentrierte sich aufs Problem von sexuellen Missbräuchen in Chile. Die Narration bezüglich dieses Themas dominierte im päpstlichen Besuch (zirka 60\% der mit diesem Thema verbundenen Nachrichten). Während der Pilgerreise konzentrierten sich die Publizisten auf die Äußerungen des Papstes bezüglich der Probleme mit den Missbräuchen in diesen Kirchen, getrauten Stewards im Flugzeug, der Kritik von Kardinälen sowie den Ordnungsunfällen. 


\subsection{Juni - die Schweiz}

Die eintägige apostolische Reise von Papst Franziskus nach der Schweiz fand am 21. Juni 2018 statt. Während des Besuchs besuchte der Papst den Weltkirchenrat in Genf. Es war der zweite Besuch des katholischen Kirchenvorstehers in diesem Land und in dieser Organisation. Früher besuchte Johannes Paul II sie im Jahre 1984.

In den analysierten Portalen wurden 10 Texte zum Thema dieses Besuchs veröffentlicht. Der erste war die Nachricht am Tag der Pilgerreise - 21. Juni 2018 im Portal www.interia.pl. Die letzte Veröffentlichung erschien sechs Tage später, am 27. Juni 2018 im gleichen Internetmedium. Die Publizisten kommentierten die päpstliche Pilgerreise im Zusammenhang mit dem Ökumenismus und seelsorgerischen Aktionen betreffend die Einheit der Christen. Die mit der Pilgerreise verbundenen Informationen erschienen am Tag der Pilgerreise. Es wurden Agenturnachrichten sowie Bilderberichte veröffentlicht (10). In der Zeit vor der päpstlichen apostolischen Reise wurden keine und danach drei Informationen veröffentlicht.

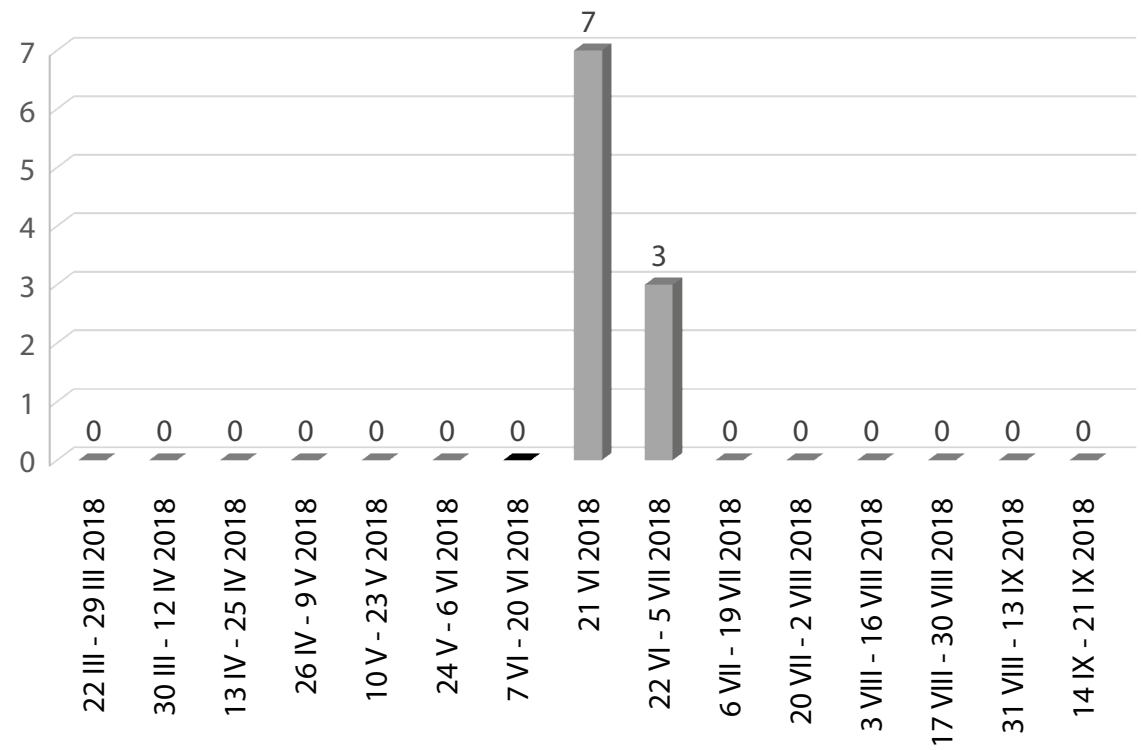

Diagramm Nr. 5. Anzahl der Publikationen zum Thema des Besuchs von Papst Franziskus in der Schweiz in den polnischen Portalen nach dem Veröffentlichungstag, $\mathrm{N}=10$

Quelle: Newspoint 
Die meisten Nachrichten zum Thema der päpstlichen Pilgerreise nach der Schweiz veröffentlichte das Portal www.interia.pl (8), was ihm rund $80 \%$ des Anteils am Markt der Internetnachrichten ausmacht. Die weiteren Portale unter Berücksichtigung der Publikationsanzahl waren entsprechend: www.onet.pl (2). Die übrigen Internetportale benachrichtigten darüber nicht.

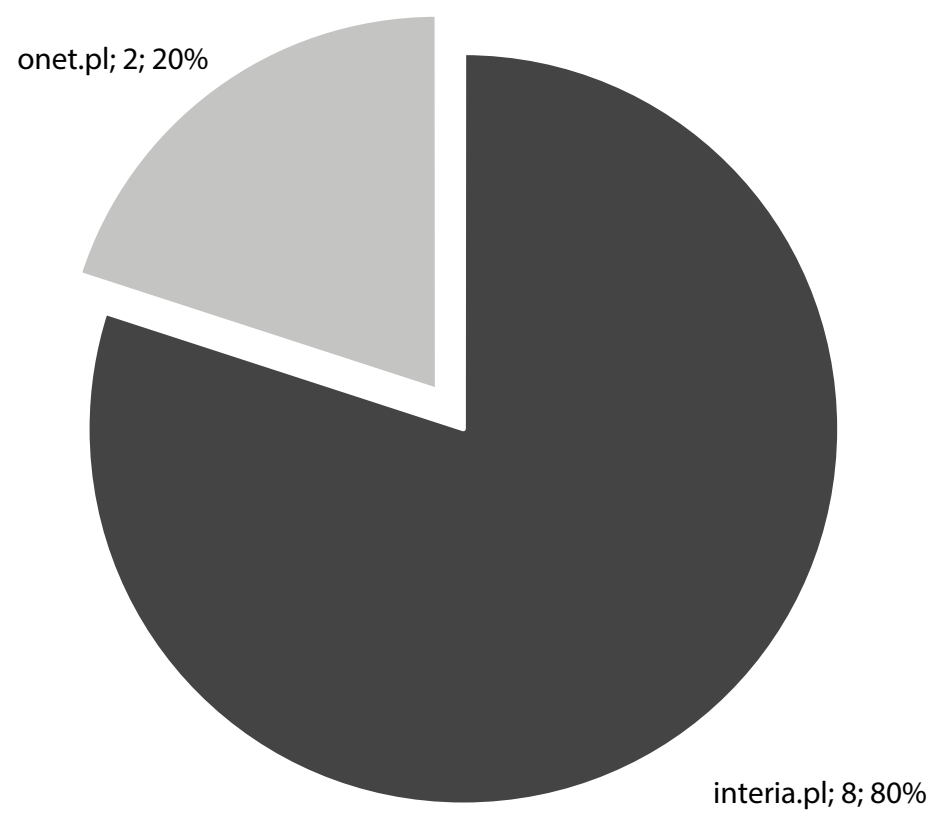

Diagramm Nr. 6. Anzahl der Publikationen zum Thema des Besuchs von Papst Franziskus in der Schweiz in den polnischen Portalen nach dem Veröffentlichungsort, $\mathrm{N}=10$

Quelle: Newspoint

Weitere Stufe der auszuführenden Forschungen war Ermittlung der Kommunikationsweise über diese apostolische Pilgerreise von Papst Franziskus. Aus den durchgeführten Forschungen geht es hervor, dass 9/10 der veröffentlichten Nachrichten neutral und eine negativ waren. Es betraf den Aufruf von Papst Franziskus zur Annahme von Immigranten.

Das Zahlenverhältnis der positiven und negativen zum Thema der besprochenen Pilgerreise Nachrichten ist aufgrund dessen, dass es lediglich neutrale bzw. positive Nachrichten waren, identisch. 


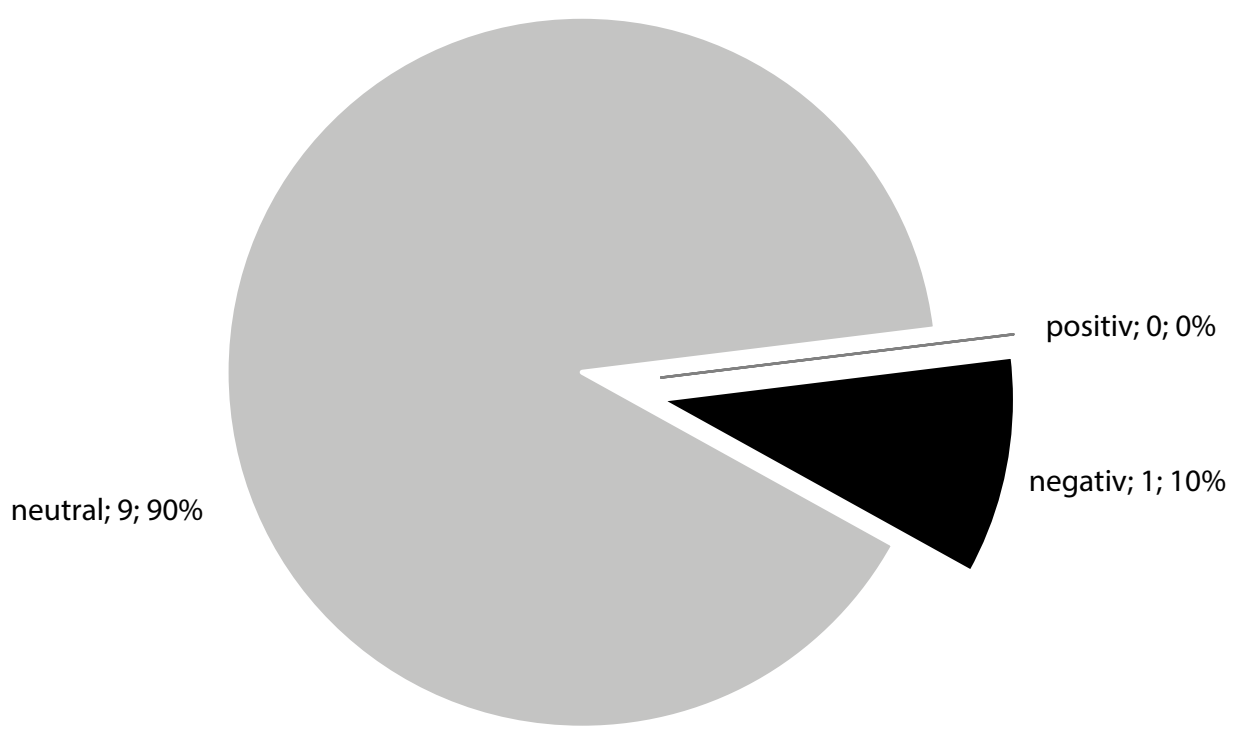

Diagramm Nr. 7. Anzahl der Publikationen zum Thema des Besuchs von Papst Franziskus in der Schweiz in den polnischen Portalen nach der Veröffentlichungsart, $\mathrm{N}=10$ Quelle: Newspoint

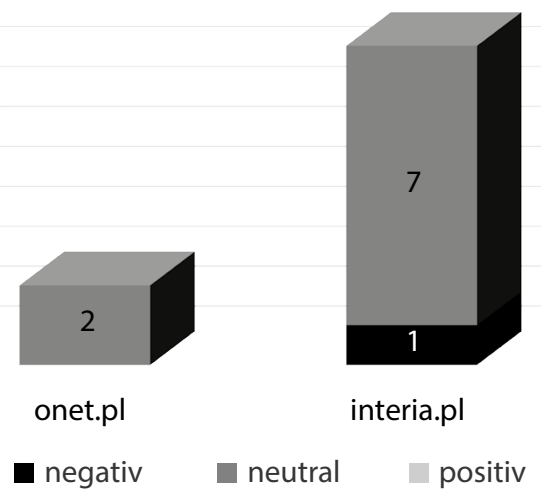

Diagramm Nr. 8. Anzahl der Publikationen zum Thema des Besuchs von Papst Franziskus in der Schweiz in den polnischen Portalen nach dem Veröffentlichungsort und -art, $\mathrm{N}=10$

Quelle: Newspoint

Die meisten geforschten Internetportale bedienen sich der Mitteilungen aus den Diensten PAP, KAI, RAI und RV bzw. Bildreportage. Die Aussage der 
Nachrichten war in neutral, ohne Angabe des Autors. Es gab keine negativen Nachrichten oder Kommentare. Materialien, die die Aussage und den Inhalt der päpstlichen Reden vertieften, wurden eher nicht veröffentlicht. Während der Pilgerreise konzentrierten sich die Publizisten auf die Äußerungen des Papstes bezüglich des Ökumenismus und der Immigranten.

\subsection{5.-26. August - Irland}

Die apostolische Reise von Papst Franziskus nach Irland fand vom 25. bis zum 26. August 2018 statt. Es war der vierundzwanzigste Pilgerreise des aus Argentinien stammenden Papstes. Während der Pilgerreise nahm der Papst an der Beendigung des 9. Weltfamilientreffens teil. Franziskus war der zweite Papst, der Irland besuchte; vor ihm besuchte Irland einmal Johannes Paul II im Jahre 1979.

Auf den analysierten Webseiten wurden 54 Texte zum Thema dieses Besuchs veröffentlicht. Die ersten waren die Informationen vom 25. zum 28. Mai 2018 im Portal www.onet.pl. Sie betrafen die in Irland durchgeführte Volksabstimmung, in der die Einwohner ihre Zustimmung gaben, die Eintragung über den Lebensschutz von Kindern ab Empfängnis zu löschen, somit Zustimmung zur Abtreibung.

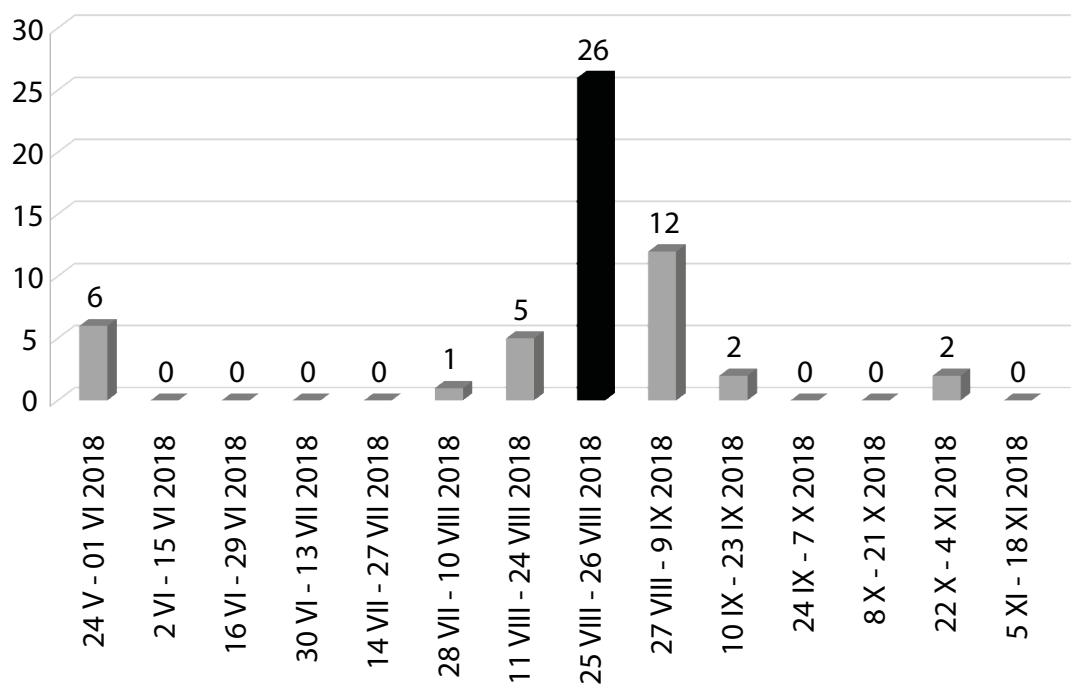

Diagramm Nr. 9. Anzahl der Publikationen zum Thema des Besuchs von Papst Franziskus in Irland in den polnischen Portalen nach dem Veröffentlichungstag, $\mathrm{N}=54$ Quelle: Newspoint 
Die Autoren zeigten dieses Ereignis im Zusammenhang mit der näher kommenden Pilgerreise von Papst Franziskus nach diesem Land. Die letzte Publikation erschien am 27. Oktober 2018 im Portal www.wp.pl. Der Autor beschäftigt sich mit der Offenbarung weiterer Verdachte hinsichtlich der Missbräuche von Minderjährigen, die in den katholischen Schulen in diesem Land stattfinden sollten. Über die Situation berichtet er als Fortsetzung des vom Papst bestimmten Vorgehens, das anstrebt, die Täter dieser Verbrechen zu entdecken und zu verurteilen, was er während der Pilgerreise nach diesem Land betonte. Die mit der Pilgerreise verbundenen Berichte wurden während ihrer Dauer und der letzte zwei Tage danach veröffentlicht. Sie betrafen am meisten die päpstliche Lehre zum Thema der Familie, der Immigranten und auch der sexuellen Missbräuche - die Narration über die letzten dominierte die mediale Übertragung. Es wurden am häufigsten Pressemitteilungen veröffentlicht (43). Es wurden 12 Nachrichten vor der päpstlichen apostolischen Reise und 16 danach veröffentlicht.

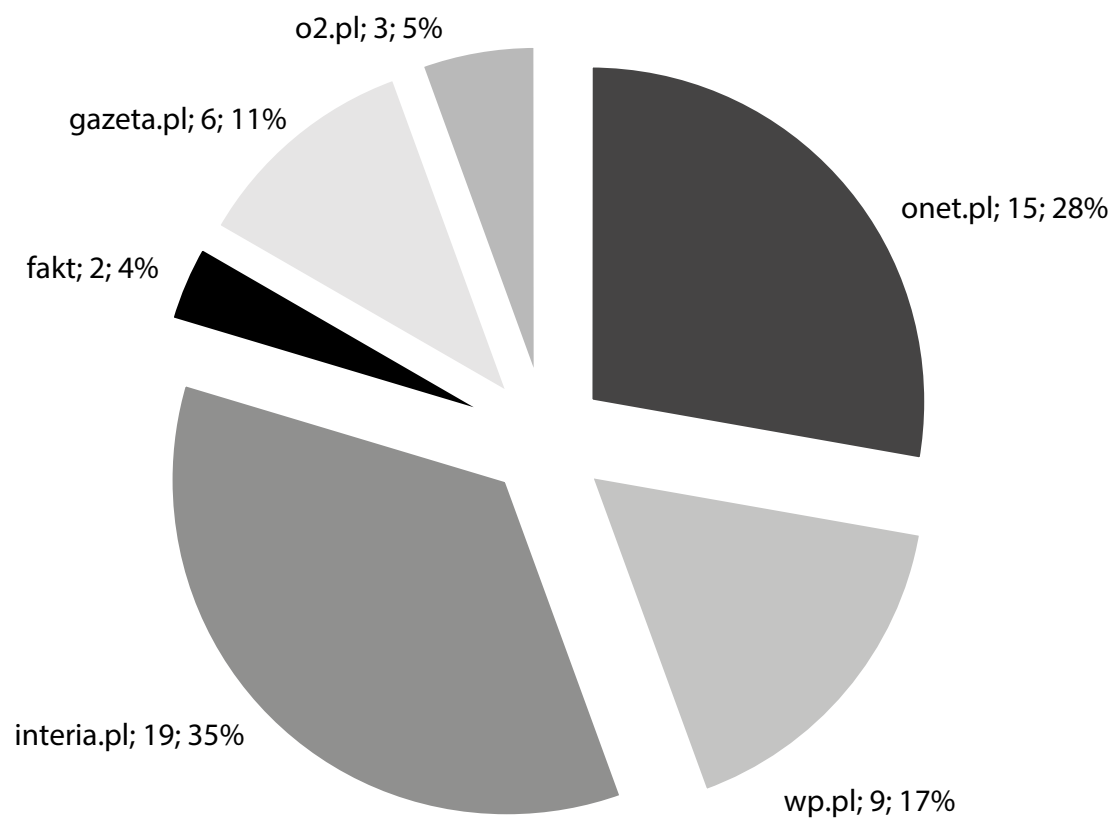

Diagramm Nr. 10. Anzahl der Publikationen zum Thema des Besuchs von Papst Franziskus in Irland in den polnischen Portalen nach dem Veröffentlichungsort, $\mathrm{N}=54$

Quelle: Newspoint 
Die meisten Nachrichten zum Thema der päpstlichen Pilgerreise nach Irland veröffentlichte das Portal www.interia.pl (19), was ihm rund 35\% des Anteils am Markt der Internetnachrichten ausmacht. Die weiteren Portale unter Berücksichtigung der Publikationsanzahl waren entsprechend: www.onet.pl (15), www. wp.pl (9), www.gazeta.pl (6), www.o2.pl (3) und www.fakt.pl (2).

Weitere Stufe der auszuführenden Forschungen war Ermittlung der Kommunikationsweise über diese apostolische Pilgerreise von Papst Franziskus. Aus den durchgeführten Forschungen geht es hervor, dass 49/54 der veröffentlichten Nachrichten positiv (3) bzw. neutral waren (46). Es wurden 5 negative Kommentare veröffentlicht. Mit Ausnahme von einem betreffen sie nicht Papst Franziskus selbst sondern die Kirche, die als eine Gemeinschaft dargestellt wurde, die nicht im Kampf gegen die Kriminalität hinsichtlich der sexuellen Missbräuche von Minderjährigen engagiert ist.

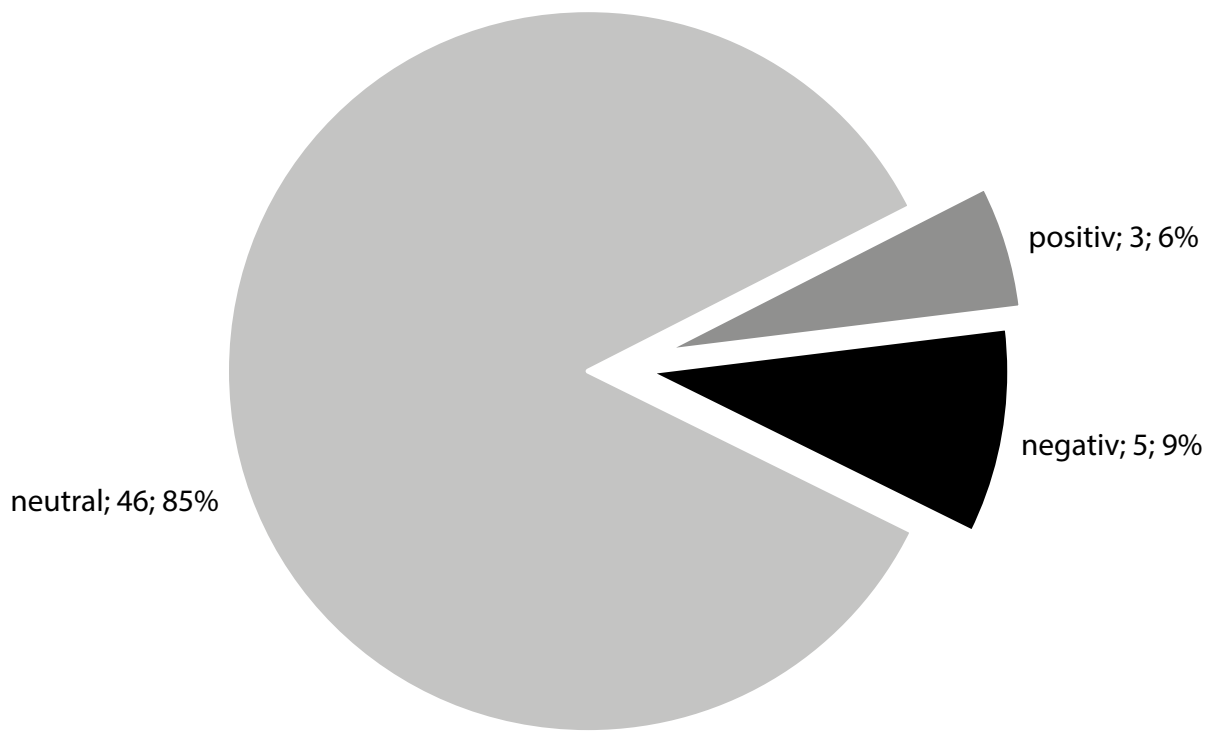

Diagramm Nr. 11. Anzahl der Publikationen zum Thema des Besuchs von Papst Franziskus in Irland in den polnischen Portalen nach der Veröffentlichungsart, N=54 Quelle: Newspoint

Der Anteil an negativen, positiven und neutralen Nachrichten war unter den analysierten Portalen vergleichbar. Die meisten negativen Informationen wurden im Portal www.onet.pl veröffentlicht. 


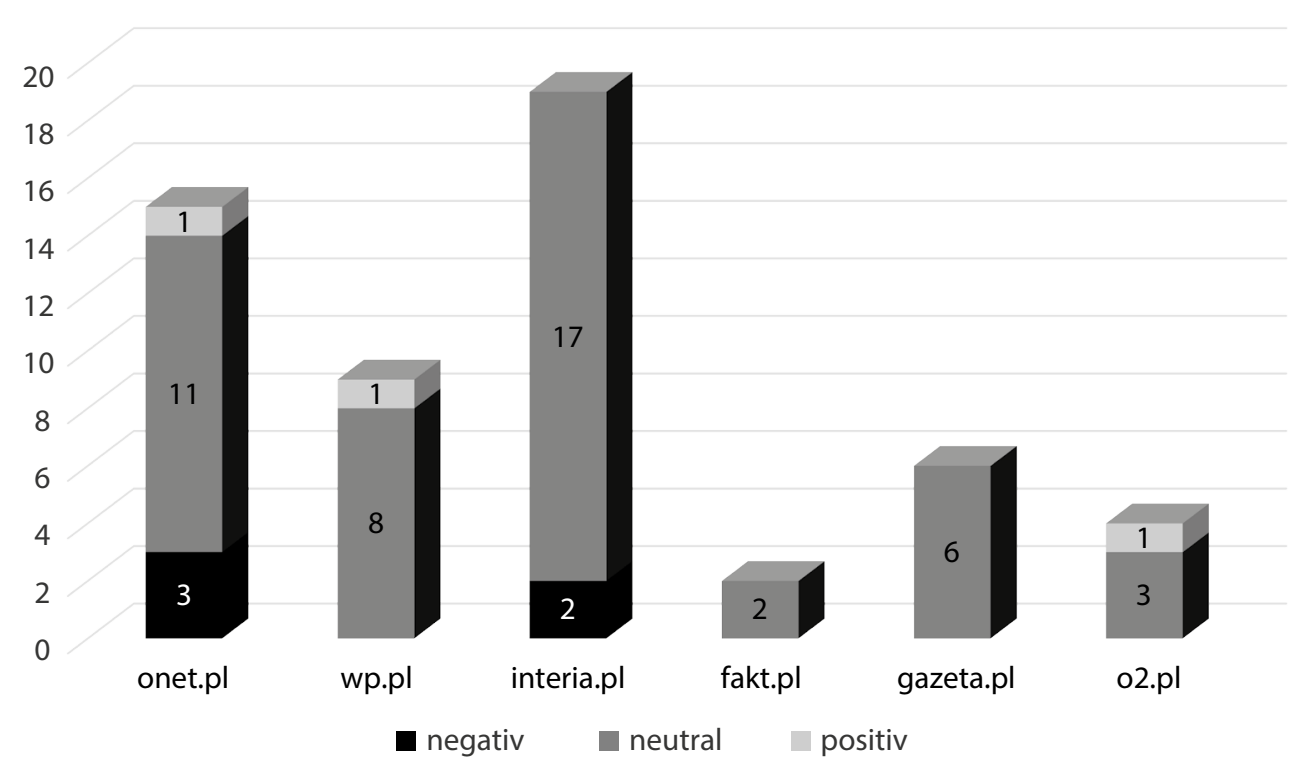

Diagramm Nr. 12. Anzahl der Publikationen zum Thema des Besuchs von Papst Franziskus in Irland in den polnischen Portalen nach dem Veröffentlichungsort und -art, N=54

Quelle: Newspoint

So wie während der analysierten Zeit der zwei ersten Pilgerreisen bedienen sich die meisten geforschten Internetportale der Mitteilungen aus den Diensten PAP, KAI, RAI und RV. Die Aussage der Nachrichten war in der Regel neutral, ohne Angabe des Autors. Die negativen Nachrichten betrafen kein Engagement der Kirche und laut den Autoren des Bischofs von Rom in die Bestrafung der in sexuelle Verbrechen gegenüber Minderjährigen verwickelten Geistlichen. Materialien, die die Aussage und den Inhalt der päpstlichen Reden vertieften, wurden wenig veröffentlicht. Am häufigsten waren sie mit dem obigen Thema sowie mit der Legalisierung von homosexuellen Ehen in Irland verbunden. Thema des 9. Weltfamilientreffens wurde, wie es scheint, in geringem Maße vernommen.

\subsection{2.-25. September - Litauen, Lettland, Estland}

Die letzte apostolische Reise von Papst Franziskus im Jahre 2018 fand in Litauen, Lettland und Estland vom 22. bis zum 25. September 2018 statt. Die Pilgerreise nach Litauen erfolgte unter dem Motto: „Jesus Christus - unsere Hoffnung“, nach Lettland: „Zeige, dass du Mutter bist“ und nach Estland: „Erwecke mein Herz“. In Litauen besuchte der Papst Vilnius und Kaunas, in Lettland Riga und Aglona und 
in Estland Tallinn. Dieser Besuch war 25 Jahre nach der ersten Auslandsreise von Johannes Paul II. nach den baltischen Ländern, der im Jahre 1993 stattfand.

In den analysierten Portalen wurden 40 Texte zum Thema dieses Besuchs veröffentlicht. Der erste war die Nachricht vom 22. September 2018 im Portal www.onet.pl. Es war die Information darüber, dass Papst Franziskus auf dem Weg nach Litauen ist und dass er ein Telegramm an Polen sendet. Früher veröffentlichten die Medien keine Informationen zur Pilgerreise. Die letzte Publikation erschien am 15. November 2018 im Portal www.interia.pl und war mit der verabschiedeten Amnestie anlässlich des hundertsten Jahrestags der Wiedererlangung der Unabhängigkeit durch Litauen und des Besuchs von Papst Franziskus in dem Land verbunden. Die mit der Pilgerreise verbundenen Berichte wurden während ihrer Dauer und der letzte zwei Tage danach veröffentlicht. Sie betrafen am meisten die päpstliche Lehre zum Thema des Friedens, des Holocausts, der sexuellen Missbräuche in der Kirche. Es wurden am häufigsten Pressemitteilungen veröffentlicht (36). In der Zeit vor der päpstlichen apostolischen Reise wurden keine und danach vier Informationen veröffentlicht. Die negativen Informationen wurden nach Beendigung des Besuchs von Franziskus in den baltischen

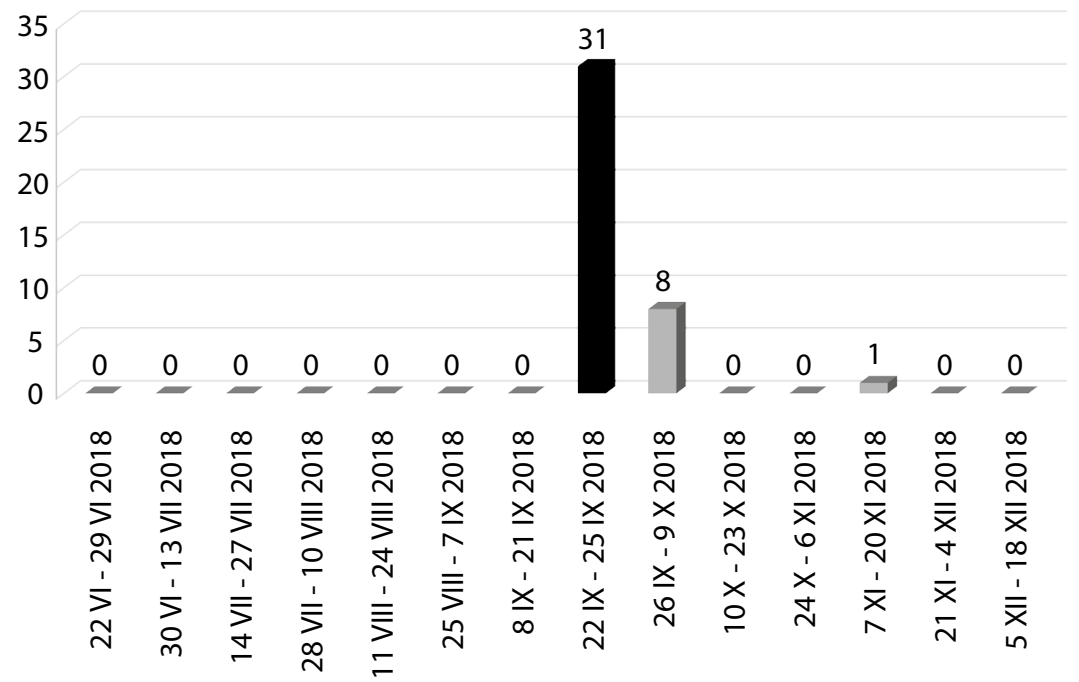

Diagramm Nr. 13. Anzahl der Publikationen zum Thema des Besuchs von Papst Franziskus in Litauen, Lettland und Estland in den polnischen Portalen nach dem Veröffentlichungstag, $\mathrm{N}=40$

Quelle: Newspoint 
Ländern veröffentlicht. Es wurde der Protest von Maciej Świrski, Präsidenten von Redoute des Guten Namens, gerichtet an Papst Franziskus veröffentlicht, in dem er Einspruch gegen eine seiner Aussagen einlegt. Sie betraf die Rolle Polens in der Geschichte Litauens.

Die meisten Nachrichten zum Thema der päpstlichen Pilgerreise nach Litauen, Lettland und Estland veröffentlichte das Portal www.interia.pl (22), was ihm rund 55\% des Anteils am Markt der Internetnachrichten ausmacht. Die weiteren Portale unter Berücksichtigung der Publikationsanzahl waren entsprechend: www.onet.pl (7), www.gazeta.pl (4), www.fakt.pl (4) und www.wp.pl (1). Im Portal www.o2.pl erschienen keine Nachrichten.

Weitere Stufe der auszuführenden Forschungen war Ermittlung der Kommunikationsweise über diese apostolische Pilgerreise von Papst Franziskus. Aus den durchgeführten Forschungen geht es hervor, dass 38/40 der veröffentlichten Nachrichten neutral (37) oder positiv (3) waren. Es wurden zwei negative Informationen veröffentlicht.

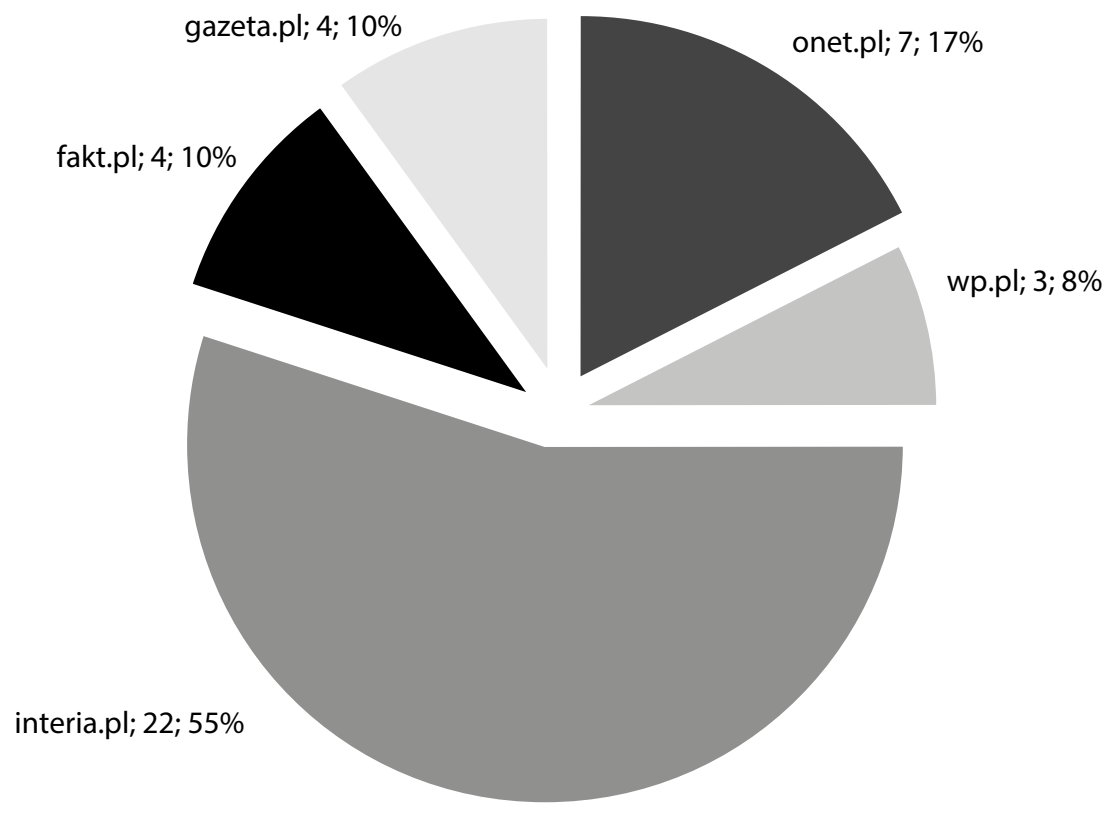

Diagramm Nr. 14. Anzahl der Publikationen zum Thema des Besuchs von Papst Franziskus in Litauen, Lettland und Estland in den polnischen Portalen nach dem Veröffentlichungsort, $\mathrm{N}=40$

Quelle: Newspoint 


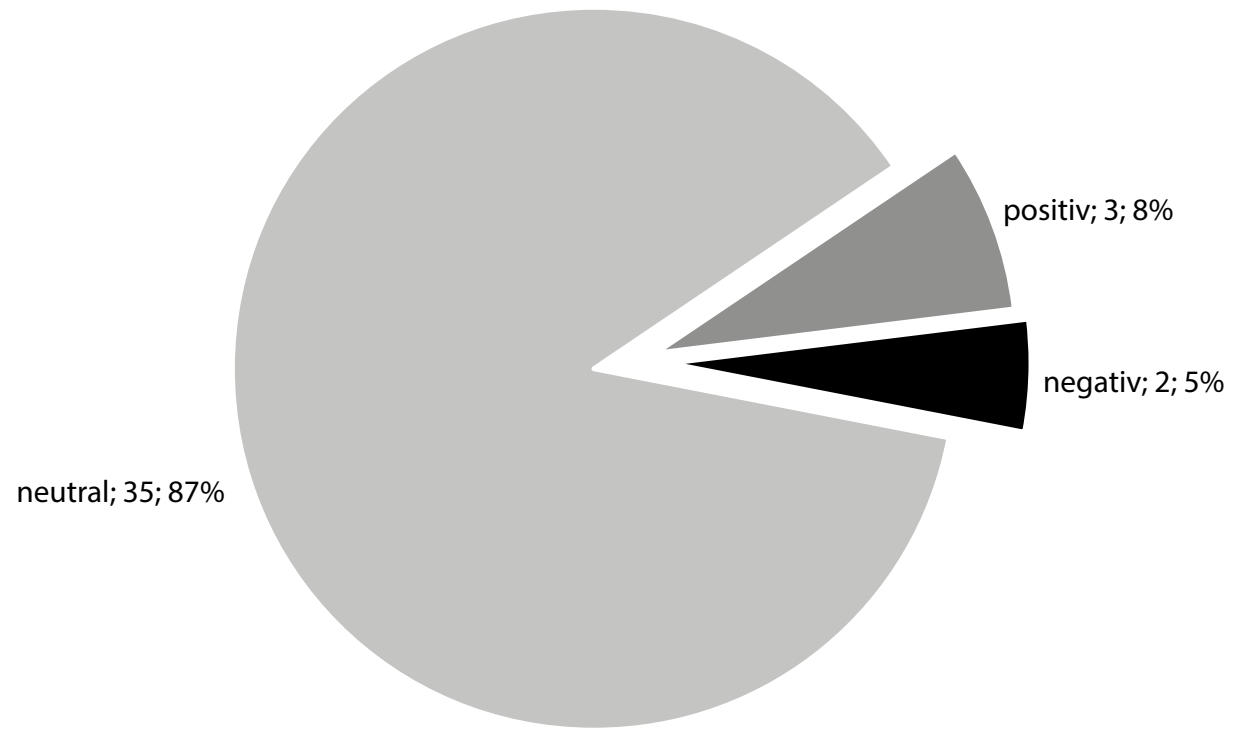

Diagramm Nr. 15. Anzahl der Publikationen zum Thema des Besuchs von Papst Franziskus in Litauen, Lettland und Estland in den polnischen Portalen, $\mathrm{N}=40$ Quelle: Newspoint

Der Anteil an negativen, positiven und neutralen Nachrichten war in der Regel in den analysierten Portalen vergleichbar. Im Portal www.interia.pl wurden die meisten eindeutig positiven Informationen, und auf www.gazeta.pl negativen veröffentlicht.

Die meisten geforschten Internetportale bedienen sich der Mitteilungen aus den Diensten PAP, KAI, RAI und RV, deshalb sind viele Publikationen neutral, nicht emotional geladen. Während der Pilgerreise erschienen ein paar Nachrichten über die Pilgerreise von Papst Franziskus nach Litauen, Lettland und Estland. Der Besuch wurde insbesondere unter Betonung der mit Polen verbundenen Orte, des Holocausts, des Totalitarismus ${ }^{10}$. Zusammenfassungen der Pilgerreise,

${ }^{10}$ Siehe [ohne Autor], Papież Franciszek na Litwie, 22 IX 2018, in: http://www.fakty.interia.pl//swiat/iId,2581575,iAId,306971, [Zugriff: 10. Februar 2020]; [ohne Autor], Litwa: 100 tysięcy osób na papieskiej mszy w Kownie, 23 IX 2018, in: http://www.fakty.interia.pl/ swiat/news-litwa-100-tysiecy-osob-na-papieskiej-mszy-w-kownie,nId,2634906, [Zugriff: 10. Februar 2020]; [ohne Autor], Papież Franciszek na Litwie. Modlił się w dawnych celach KGB, w których torturowano więźniów, 23 IX 2018, in: http://www.wiadomosci.gazeta.pl/wiadomosci/7,114881,23959838,papiez-franciszek-na-litwie-modlil-sie-w-dawnych-celach-kgb. html, [Zugriff: 10. Februar 2020]; [ohne Autor], Papież na kolanach $w$ więziennej celi. Tam 


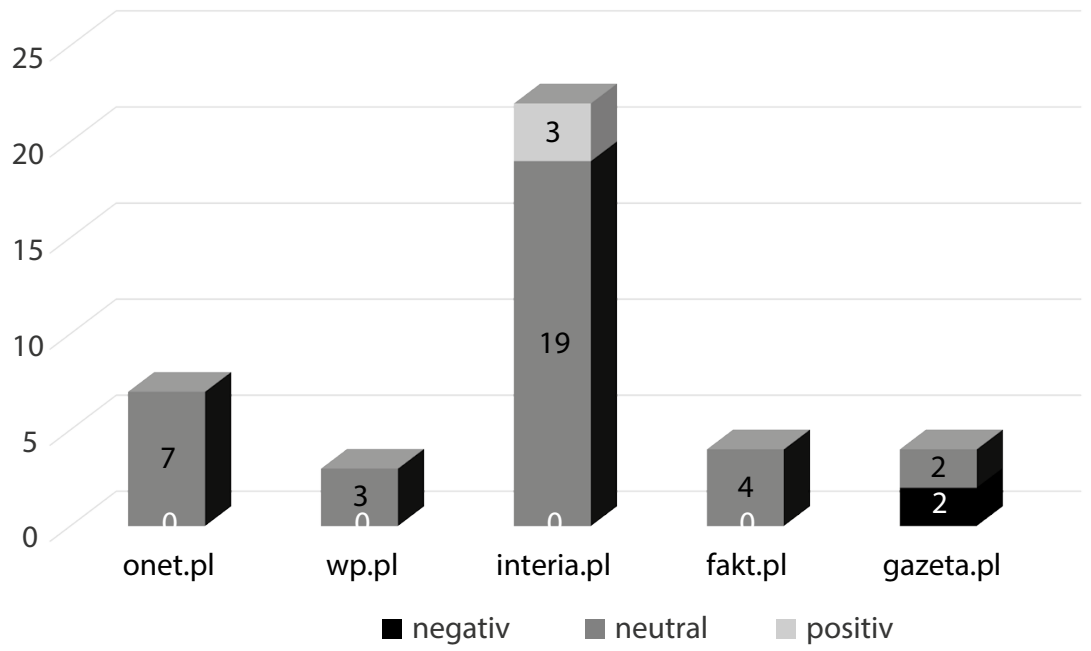

Diagramm Nr. 16. Anzahl der Publikationen zum Thema des Besuchs von Papst Franziskus in Litauen, Lettland und Estland nach dem Veröffentlichungsort und -art, $\mathrm{N}=40$

Quelle: Newspoint

der Reflexionen, darunter theologisch, wurden meistens nicht veröffentlicht. Die einzigen Informationen betrafen die Rolle des Kreuzes und der Barmherzigkeit im christlichen Leben ${ }^{11}$. Die letzten Nachrichten fielen mit dem letzten Tag der Pilgerreise zusammen, obwohl sie aufgrund des Zeitunterschieds ein Tag später veröffentlicht wurden.

\section{THEOLOGISCHE ANALYSE DER VERÖFFENTLICHTEN INHALTE}

Die meisten Nachrichten bezüglich der päpstlichen Pilgereisen waren Agenturnachrichten, am häufigsten nach der Katholischen Informationsagentur (KAI), der Polnischen Nachrichtenagentur (PAP) und der Rundfunkinformationsagentur

bito i torturowano więźniów, 24 IX 2018, in: http://www.fakt.pl/wydarzenia/swiat/papiezfranciszek-na-kolanach-w-wieziennej-celi-w-wilnie-na-litwie/8hqymbt [Zugriff: 10. Februar 2020]; [ohne Autor], Papież w Estonii: Niektórzy grożąc broniq̨ i wojskiem, wydaja się silniejsi, 25 IX 2018, in: http://www.fakty.interia.pl/swiat/news-papiez-w-estonii-niektorzy-grozacbronia-i-wojskiem-wydaja-s,nId,2636038, [Zugriff: 10. Februar 2020].

${ }^{11}$ Siehe [ohne Autor], Litwa: 100 tysięcy osób na papieskiej mszy w Kownie, 23 IX 2018, in: http://www.fakty.interia.pl/swiat/news-litwa-100-tysiecy-osob-na-papieskiej-mszy-w-kownie,nId,2634906, [Zugriff: 10. Februar 2020]. 
(RAI), dem Radio Vatikan (RV) veröffentlicht. Ihre Anzahl beträgt 148 von 174, was $\mathbf{8 5 , 1 \%}$ der gesamten Informationen darstellt. Es sind Inhalte, die ohne Angabe des Autors und dupliziert ohne Beurteilung des jeweiligen Ereignisses bzw., am häufigsten, der päpstlichen Lehre veröffentlicht werden. Die gleiche Nachricht erscheint in mehreren Internetportalen. Die Nachrichtenagenturen konzentrieren sich fast ausschließlich auf neutrale Nachrichten ohne emotionale Auswertung und auf päpstliche Pilgerreisen werden keine dedizierten Journalisten entsandt. Dies geschieht aus finanziellen Gründen und auch wegen keinem größeren Interesse für die Pilgerreisen, was die niedrige Anzahl der Nachrichten zeigt. Negative Informationen werden gleichmäßig in verschiedenen Portalen veröffentlicht, man kann somit nicht feststellen, dass die päpstliche Lehre und die Person des Papstes in einem der Portale in höherem Maße infrage gestellt wird. Die am meisten in der Medienübertragung vorkommenden Agenturmitteilungen informieren über die gegebenen Ereignisse, sie kommentieren sie allerdings selten. Unter den Publikationen beziehen sich die meisten auf Organisationsangelegenheiten oder auf Sachen, die nicht direkt mit dem Inhalt der päpstlichen Lehre zusammenhängen sowie, wie es im Forschungsjahr 2018 bemerkbar ist, auf die Sachen im Zusammenhang mit den sexuellen Missbräuchen von Minderjährigen und Unselbständigen durch Geistlichen, was in vielen Fällen fast vollständig die Narration betreffend die päpstliche Pilgerreise erfüllte.

Die erste apostolische Reise von Papst Franziskus im Jahre 2018 erfolgte nach Chile und Peru (vom 15. bis zum 21. Januar 2018). In Chile wurden heilige Messen in Santiago, Temuco und Iquique mit Teilnahme von ein paar hundert Tausend Gläubiger gehalten. Der Papst traf sich mit den einheimischen Völkern, Immigranten, Gefängnisinsassinnen, der Geistlichkeit, den Bischöfen, der Jugend, dem Universitätskreis und den Opfern der Pädophilie - es waren die Hauptereignisse des apostolischen Besuchs unter dem Motto „Meinen Frieden gebe ich euch“. Es war die 22. Auslandsreise von Papst Bergoglio und sein sechster Aufenthalt auf dem südamerikanischen Kontinent. Heiliger Vater versuchte insbesondere die örtliche Kirche zu unterstützen, die hauptsächlich wegen zahlreiche Fälle von Pädophilie unter den Geistlichen in der Krise versunken ist. Bereits in seiner ersten Rede - an die chilenischen Behörden - drückte er Kummer und Scham angesichts der den Kindern durch Kirchendiener zugefügten Schäden ohne zu zögern aus. Franziskus sprach nicht nur über dieses Thema, er traf sich auch mit den Opfern der Missbräuche. In seiner Rede an die Bischöfe sagte er wiederum 
sein kategorisches „Nein“ für den Klerikalismus aus. Der Papst sprach auch die Sache der Diskriminierung und der Verfolgungen der einheimischen Völker, insbesondere Mapuche an, die ihrerseits immer öfter Gewalt verüben, darunter Anstecken von christlichen Tempeln. In Peru hielt er zwei hl. Messen in Trujillo und Lima, jede mit der Teilnahme von ca. eine Million Gläubiger, Treffen mit der Bevölkerung von Amazonien, Vertretern der Behörden, der Geistlichkeit, Klausurordensschwestern, der Jugend und den Bischöfen. Das Motto war: „Geeint in der Hoffnung“. Der Papst konzentrierte sich auf die tiefen Probleme von Amazonien. Während de Treffens mit den Völkern wies er besonders auf die Zerstörungen im Zusammenhang mit dem Raubabbau der Ressourcen, dem Menschenhandel, genötigte Arbeitskräfte, sexueller Ausnutzung von Frauen, der Ausgrenzung und der Diskriminierung hin. Heiliger Vater verurteile ausdrücklich den Kulturkolonialismus und wies auf die Notwendigkeit der interkulturellen Bildung hin. Während des Treffens mit den peruanischen Behörden rief der Papst auch mit starken Worten auf, die Personen und lokale Völker anzuhören, anzuerkennen, zu respektieren sowie die integrale Ökologie als Alternative für den sozialen $\mathrm{Ab}$ stieg und die Umweltzerstörung zu fördern und zur entwickeln. Er betonte, dass das einzige Rezept für das Phänomen der Korruption größere Transparenz zwischen den öffentlichen Behörden, dem Privatsektor und der Bürgergesellschaft sind. Aufgrund der Mediennachrichten, die zu dieser Zeit erschienen, dominierte die Übertragung der Pilgerreise das Problem der Pädophilie. Ein anderes Thema waren die getrauten Stewards des Flugzeugs, mit dem der Bischof von Rom reiste. Die dargestellten theologischen Inhalte waren mit der sozialen Kirchenlehre verbunden ${ }^{12}$.

${ }^{12}$ Siehe [ohne Autor], Papież prosi o wybaczenie za skandal pedofilii $w$ Kościele, 16 I 2018, in: http://www.wiadomosci.onet.pl/swiat/papiez-prosi-o-wybaczenie-za-skandalpedofilii-w-kosciele/lw7q84j, [Zugriff: 7. Februar 2020]; K. Błaszkiewicz, Papież przeprasza za księży-pedofilów. Przełomowe słowa, 17 I 2018, in: http://www.wiadomosci.wp.pl/ papiez-przeprasza-za-ksiezy-pedofilow-przelomowe-slowa-6210239147264129a, [Zugriff: 7. Februar 2020]; [ohne Autor], Atak na Franciszka podczas pielgrzymki w Chile. Ochrona nie uchroniła papieża przed uderzeniem, 17 I 2018, in: http://www.wiadomosci.gazeta.pl/ wiadomosci/7,114881,22910539,to-nie-jest-latwa-pielgrzymka-najpierw-podpalono-koscioly.html, [Zugriff: 7. Februar 2020]; [ohne Autor], Papież: nie ma chrześcijańskiej radości, gdy zamyka się drogę imigrantom, 18 I 2018, in: http://www.fakty.interia.pl/swiat/news-papiez-nie-ma-chrzescijanskiej-radosci-gdy-zamyka-sie-drzwi-,nId,2510300, [Zugriff: 7 Februar 2020]; [ohne Autor], Papież Franciszek udzielił ślubu na pokładzie samolotu, 18 I 2018, in: 
Das Gebet und das ökumenische Treffen im Ökumenischen Zentrum des Weltkirchenrats (WKR), der das Jubiläum von 70 Jahren feiert, Mittagessen im Ökumenischen Institut in Bossey und hl. Messe mit der Teilnahme von mehr als 40 Tsd. schweizerischer Katholiken bildeten die zehnstündige „ökumenische Pilgerreise" von Franziskus am 21. Juni nach Genf in der Schweiz. Sie verlief unter dem Motto „Gemeinsam gehen, beten und arbeiten“. Heiliger Vater wies darauf hin, dass die Kirche einen neuen Evangelisierungsschwung braucht. Während der hl. Messe betonte er wiederum die Bedeutung des Treffens und des gemeinsamen Gebets. Das Hauptthema in der Pressenarration war das Problem der Christeneinheit und des Ökumenismus ${ }^{13}$.

http://www.wiadomosci.onet.pl/swiat/papiez-franciszek-udzielil-slubu-na-pokladzie-samolotu/9mlxhty, [Zugriff: 7. Februar 2020]; [ohne Autor], Papież przeprosił za słowa o biskupie z Chile w zwiq̨zku z pedofiliq, 22 I 2018, in: http://www.wiadomosci.onet.pl/swiat/papiezprzeprosil-za-slowa-o-biskupie-z-chile-w-zwiazku-z-pedofilia/hpl4mxj, [Zugriff: 7. Februar 2020]; [ohne Autor], Papież Franciszek wzywa do walki z plaga zabójstw kobiet w Ameryce Południowej, 21 I 2018, in: http://www.wiadomosci.onet.pl/swiat/papiez-franciszek-wzywa-do-walki-z-plaga-zabojstw-kobiet-w-ameryce-poludniowej/beb7q66, [Zugriff: 7. Februar 2020]; B. Goluch, Papież Franciszek przeprasza za wypowiedź na temat pedofilii. "Użyłem złych słów", 22 I 2018, in: http://www.o2.pl/artykul/papiez-franciszek-przeprasza-za-wypowiedz-na-temat-pedofilii-uzylem-zlych-slow-6212158191376513a, [Zugriff: 7. Februar 2020]; K. Winogrodzki, Papież Franciszek wysyła delegata. Zbada sprawę pedofilii, 30 I 2018, in: http://www.wiadomosci.wp.pl/papiez-franciszek-wysyla-delegata-zbada-sprawe-pedofilii-6214996304033409a, [Zugriff: 7. Februar 2020]; M. Kolewska, Papież Franciszek przeprasza. "Odczuwam ból i wstyd", 12 IV 2018, in: http://www.wiadomosci.wp.pl/papiez-franciszekprzeprasza-odczuwam-bol-i-wstyd-6240279096924289a, [Zugriff: 7. Februar 2020].

${ }^{13}$ Siehe [ohne Autor], Papież Franciszek odwiedza Szwajcarię, 21 VI 2018, in: http:// www.fakty.interia.pl/swiat/,ild,2536808,iAId,297896, [Zugriff: 7. Februar 2020]; [ohne Autor], Papież Franciszek odwiedził Szwajcarię, 21 VI 2018, in: http://www.fakty.interia.pl/galerie/swiat/zdjecie,iId,2536804,iAId,297896, [Zugriff: 7. Februar 2020]; [ohne Autor], Papież Franciszek krytykuje podziały wśród chrześcijan, 21 VI 2018, in: http://www.wiadomosci. onet.pl/swiat/papiez-franciszek-krytykuje-podzialy-wsrod-chrzescijan/jh0d9f4, [Zugriff: 7. Februar 2020]; [ohne Autor], Papież: podziały wśród chrześcijan, zgorszeniem dla świata, 21 VI 2018, in: http://www.fakty.interia.pl/religia/news-papiez-podzialy-wsrod-chrzescijan-sa-zgorszeniem-dla-swiata,nId,2596932, [Zugriff: 7. Februar 2020]; [ohne Autor], Papież Franciszek: każdy kraj powinien przyjmować migrantów z rozwaga, 20 I 2018, in: http://www. wiadomosci.onet.pl/swiat/papiez-franciszek-kazdy-kraj-powinien-przyjmowac-migrantowz-rozwaga/dj4v3jc, [Zugriff: 7. Februar 2020]; [ohne Autor], Papież: należy przyjmować tylu migrantów, ilu można, 22 VI 2018, in: http://www.fakty.interia.pl/religia/news-papiez-nalezy-przyjmowac-tylu-migrantow-ilu-mozna,nId,2597139, [Zugriff: 7. Februar 2020]; [ohne Autor], Papież Franciszek odwiedził Szwajcarię, 27 VI 2018, in: http://www.fakty.interia.pl/ swiat/iId,2536807,iAId,297896, [Zugriff: 7. Februar 2020]. 
9. Weltfamilientreffen in Irland mit der Teilnahme von Franziskus fand unter dem Motto: „Das Evangelium der Familie, Freude für die Welt“ vom 25. bis zum 26. August statt. Es bestand aus einem Treffen mit Vertretern der Behörden, der Bürgergesellschaft und des diplomatischen Corps im Dubliner Schloss, mit den Ehen sowie Verlobten in der Prokathedrale der Unbefleckten Empfängnis der Hl. Jungfrau Maria, Teilnahme an der Familienfeier im Stadium Croke Park mit 80 Tsd. Menschen, Besuch im Marienheiligtum in Knock sowie hl. Messe mit der Teilnahme von ca. 130 Tsd. Gläubiger in Dublin. Während der hl. Messe in Dublin zum Schluss des Ereignisses ermutigte der Papst, das Evangelium der Familie als Freude für die Welt mit anderen zu teilen. Im Rahmen des Bußgebets bat er Gott um Vergebung für die Missbräuche der Macht, des Gewissens und sexuelle Missbräuche, zu den es in den kirchlichen Institutionen in Irland kam und fürs mangelnde Mitgefühl der kirchlichen Vorgesetzten für die Opfer. Die journalistische Narration wurde vom Problem der sexuellen Missbräuche von Minderjährigen in der Kirche, der Seelsorge von homosexuellen Personen, jedoch auch, obwohl im geringerem Maße, von den theologischen mit der Ehe verbundenen Inhalten dominiert ${ }^{14}$.

${ }^{14}$ Siehe [ohne Autor], Papież spotka się z ofiarami pedofilii podczas wizyty $w$ Irlandii, 21 VIII 2018, in: http://www.fakty.interia.pl/swiat/news-papiez-spotka-sie-z-ofiarami-pedofiliipodczas-wizyty-w-irla,nId,2621458, [Zugriff: 10. Februar 2020]; [ohne Autor], Papież Franciszek odwiedza wstrzq̨sanq kościelnymi skandalami Irlandię, 24 VIII 2018, in: http://www. wiadomosci.onet.pl/swiat/papiez-franciszek-odwiedza-wstrzasana-koscielnymi-skandalami-irlandie/8950yrm, [Zugriff: 10. Februar 2020]; [ohne Autor], Papież spotka się z ofiarami pedofilii podczas wizyty w Irlandii, 25 VIII 2018, in: http://www.wiadomosci.onet.pl/swiat/irlandia-papiez-franciszek-spotkal-sie-z-ofiarami-pedofilii/0zjz9gr, [Zugriff: 10. Februar 2020]; [ohne Autor], Papież: małżeństwo jest ryzykiem. Ryzykujcie, 25 VIII 2018, in: http://www. fakty.interia.pl/raporty/raport-nowy-papiez/aktualnosci/news-papiez-malzenstwo-jest-ryzykiem-ryzykujcie,nId,2623132, [Zugriff: 10. Februar 2020]; [ohne Autor], Irlandia: 300 tys. osób na papieskiej mszy w Dublinie, 26 VIII 2018, in: http://www.fakty.interia.pl/swiat/newsirlandia-300-tys-osob-na-papieskiej-mszy-w-dublinie,nId,2623313, [Zugriff: 10. Februar 2020]; N. Durman, „Błagam Boga”. Emocjonalna przemowa Franciszka do dziesiątków tysięcy wiernych. Rozległy się brawa, 27 V 2018, in: http://www.wiadomosci.wp.pl/blagam-bogaemocjonalna-przemowa-franciszka-do-dziesiatkow-tysiecy-wiernych-rozlegly-sie-brawa6288503027398273a, [Zugriff: 10. Februar 2020]; [ohne Autor], Papież do rodziców homoseksualistów: należy rozmawiać, nie potępiać, 28 VIII 2018, in: http://www.wiadomosci.onet.pl/ swiat/papiez-do-rodzicow-homoseksualistow-nalezy-rozmawiac-nie-potepiac/cst9yrt, [Zugriff: 10. Februar 2020]; [ohne Autor], Papież przybył do Irlandii. „Podzielam zgorszenie i oburzenie z powodu pedofilii", 28 VIII 2018, in: http://www.fakty.interia.pl/swiat/news-papiezprzybyl-do-irlandii-podzielam-zgorszenie-i-oburzenie-,nId,2623060, [Zugriff: 10. Februar 
Das Hauptmotiv des Besuchs von Franziskus in Litauen am 22. und 23. September war der Appell um „Hinausgehende Kirche“ gegenüber den heutigen Randzonen und um die Hoffnung. Die Pilgerreise verlief nach dem Motto: „Jesus Christus - unsere Hoffnung“. Dieses Land war die erste Etappe des päpstlichen Besuch in den baltischen Ländern. In Vilnius ermutigte Heiliger Vater die Jugend, an der „Revolution der Sensibilität" teilzunehmen. Er betete auch am Spitzen Tor und am Grab von hl. Kasimir - Patron Litauens. Während der hl. Messe am Sonntag in Kaunas rief die Minderheit zur Offenheit auf, die in Litauen leben. Die Aussagen zur Wahrnehmung und zum Zuhören von Ausgeschlossenen ist ein festes Element der Narration des Papstes. Papst Franziskus bat die Geistlichen, nicht „Beamten Gottes“ zu werden. In ehemaliger Folterkammer von KGB in Vilnius betete er für die Opfer des Totalitarismus. Die zweite Etappe des Besuchs war Lettland, wo der Papst am 24. September Riga und Aglona besuchte. In der Hauptstadt traf er sich mit den Behörden des Landes und anschließend fand ein ökumenisches Treffen mit Vertretern von 10 Kirchen in der lutherischen Kathedrale statt. Am Nachmittage begab sich Franziskus zum nationalen Marienheiligtum in Aglona. Er sprach dort über Lettland als einen Ort des Dialogs und des Treffens sowie friedlicher Koexistenz, der versucht in die Zukunft zu schauen. Die dritte Etappe der päpstlichen Reise (25. September) war Estland. Hier gab es Treffen: mit Vertretern der Behörden und der Bürgergesellschaft, ökumenisches mit der Jugend in lutherischer Kirche hl. Karl und auch mit Bedürftigen und Armen, den kirchliche karitative Organisationen in der Kathedrale Hl. Peter und Paul helfen. Franziskus hielt hl. Messe am Friedensplatz in Tallinn mit der Teilnahme von fast allen örtlichen Katholiken, deren Zahl knappe 6 Tsd. beträgt, und auch von Christen anderer Konfessionen. Das Holocaust, totalitäre Regimes und auch evangelische

2020]; [ohne Autor], Papież: podzielam zgorszenie i oburzenie z powodu pedofilii, 25 VIII 2018, in: http://www.wiadomosci.onet.pl/swiat/papiez-w-irlandii-podzielam-oburzenie-z-powodu-pedofilii/k3s86pw, [Zugriff: 10. Februar 2020]. [ohne Autor], Abp Viganò oskarża papieża o tuszowanie skandalu. Dlaczego Franciszek nie zamierza komentować jego tez?, 28 VIII 2018, in: http://www.wiadomosci.onet.pl/religia/opinie/abp-vigano-oskarza-papieza-o-tuszowanie-skandalu-dlaczego-franciszek-nie-zamierza/2hmcrzc, [Zugriff: 10. Februar 2020]; B. Goluch, Papież Franciszek: Kościół przeżywa trudny moment. Musimy go bronić, 27 X 2017, in: http://www.wiadomosci.wp.pl/papiez-franciszek-kosciol-przezywa-trudny-moment-musimy-go-bronic-6310577144174209a, [Zugriff 25 III 2018]. 
Marcin Wrzos, Apostolische Auslandsreisen von Papst Franziskus, darunter Missionsreisen...

Wiederholung des Aufrufs zum Dialog und zur Einheit dominierten die journalistische Narration ${ }^{15}$.

Bei den die päpstlichen Auslandspilgerreisen im Jahre 2018 betreffenden Publikationen geht es in den analysierten Internetportalen in fast 83\% um Mitteilungen von Nachrichtenagenturen. Es kommt vor, dass die Mitteilungen in verschiedenen Internetdiensten kopiert werden. Es sind somit weder umfangreiche noch vertiefte Kommentare hinsichtlich der päpstlichen Lehre. Sichtbar ist die Tendenz zu immer kürzeren Berichten aus den päpstlichen Pilgereisen in den inländischen Internetportalen. Die päpstlichen Pilgerreisen im Jahre 2017 waren insbesondere mit dem Ökumenismus, dem religionsübergreifenden Dialog, den Flüchtlingen, der Friedenseinführung oder Evangelisierung durch Arbeit zugunsten der ausgeschiedenen Menschen verbunden. Die in den Laienmedien veröffentlichten theologischen Inhalte waren somit mit der Ekklesiologie, der Theologie

${ }^{15}$ Siehe [ohne Autor], Litwa: Kilkadziesiąt tysięcy osób oczekiwanych na papieskiej mszy $w$ Kownie, 22 IX 2018, in: http://www.fakty.interia.pl/swiat/news-litwa-kilkadziesiat-tysiecy-osob-oczekiwanych-na-papieskiej-,nId,2634878, [Zugriff: 10. Februar 2020]; [ohne Autor], Papież Franciszek na Litwie, 22 IX 2018, in: http://www.fakty.interia.pl// swiat/iId,2581575,iAId,306971, [Zugriff: 10. Februar 2020]; [ohne Autor], Litwa: 100 tysięcy osób na papieskiej mszy w Kownie, 23 IX 2018, in: http://www.fakty.interia.pl/swiat/news-litwa-100-tysiecy-osob-na-papieskiej-mszy-w-kownie,nId,2634906, [Zugriff: 10. Februar 2020]; [ohne Autor], Papież Franciszek na Litwie. Modlił się w dawnych celach KGB, w których torturowano więźniów, 23 IX 2018, in: http://www.wiadomosci.gazeta.pl/wiadomosci/7,114881,23959838,papiez-franciszek-na-litwie-modlil-sie-w-dawnych-celach-kgb. html, [Zugriff: 10. Februar 2020]; [ohne Autor], Papież Franciszek: okupacja, udręka deportowanych, groza gett i Syberii, 23 IX 2018, in: http://www.wiadomosci.onet.pl/swiat/papiezfranciszek-o-historii-na-litwie/b8h81es, [Zugriff: 10. Februar 2020]; [ohne Autor], Papież oddał hołd ofiarom getta $w$ Wilnie, 23 IX 2018, in: http://www.fakty.interia.pl/raporty/raport-nowy-papiez/aktualnosci/news-papiez-franciszek-oddal-hold-ofiarom-getta-w-wilnie,nId,2634998 [Zugriff: 10. Februar 2020]; [ohne Autor], Papież na kolanach $w$ więziennej celi. Tam bito i torturowano więźniów, 24 IX 2018, in: http://www.fakt.pl/wydarzenia/swiat/papiez-franciszek-na-kolanach-w-wieziennej-celi-w-wilnie-na-litwie/8hqymbt [Zugriff: 10. Februar 2020]; [ohne Autor], Papież Franciszek: niesienie pomocy nie może być turystykq solidarnościowq, 24 IX 2018, in: http://www.wiadomosci.onet.pl/religia/aktualnosci/papiezfranciszek-niesienie-pomocy-nie-moze-byc-turystyka-solidarnosciowa/pv3jm3x, [Zugriff: 10. Februar 2020]; [ohne Autor], Papież w Estonii: Niektórzy grożąc broniq̨ i wojskiem, wydają się silniejsi, 25 IX 2018, in: http://www.fakty.interia.pl/swiat/news-papiez-w-estonii-niektorzygrozac-bronia-i-wojskiem-wydaja-s,nId,2636038, [Zugriff: 10. Februar 2020]; [ohne Autor], apież na mszy w Tallinie: nie zdobyliście wolności, by stać się niewolnikami konsumpcjonizmu, 25 IX 2018, in: http://www.wiadomosci.onet.pl/religia/aktualnosci/papiez-na-mszy-w-tallinie-nie-zdobyliscie-wolnosci-by-stac-sie-niewolnikami/hgtze7g, [Zugriff: 10. Februar 2020]. 
der Barmherzigkeit, der Moraltheologie, der Theologie der Geistigkeit, dem Dialog, dem Ökumenismus und dem religionsübergreifenden Dialog verbunden. Man konzentrierte sich darin auf der Darstellung der überzeugenden Kirche, die nach Papst Franziskus eine solche wird, wenn sie beginnt, mit Sorge um den Menschen, insbesondere um den ausgeschlossenen und ausgeschiedenen zu leben.

\section{PASTORALE SCHLUSSFOLGERUNGEN}

Die erste Papstbotschaft zum Welttag der Massenmedien wurde nach dem 2. Vatikanischen Konzil im Jahre 1967 vom Papst Paulus VI. veröffentlicht. Es betonte die Betrachtung der sozialen Kommunikationsmittel als eines wichtigen Kommunikationswerkzeugs ${ }^{16}$. Die mit neuen Medien, darunter mit den Portalen zusammenhängenden Inhalte wurden darin allerdings erst ab 1990 aufgenommen, als die päpstliche Definition des Internets zum ersten Mal veröffentlicht wurde: „computerisiertes Teilnahmesystem“17. Es war sowieso eine schnelle Reaktion aufs Erscheinen des Internets, das ein Hauptträger neuer Medien ist. Johannes Paul II sprach sie immer öfter in seinen Botschaften direkt an, was zu einer Regel ab 2009, d. h. ab den Pontifikaten von Benedikt XVI. und dann von Franziskus wurde. Mit der Zeit begannen zusammen mit der Entwicklung der Digital- und Medientechnik folgende Begriffe in den analysierten Botschaften zu erscheinen: „neue Medien“, „Globalisierung“, „Mobiltelefone“, „Cyberspace“, „SMS“, „Android“, „Fakenews“ oder „Deepfake“18. Die Päpste wiesen immer auf die Rolle dieser Medien in der Gestaltung der heutigen Zivilisation hin, sowohl auf die Chance, die dieser Raum gibt, als auch auf die Gefahren. Die Frage der Algorithmen, die unsere Interaktionen in den sozialen Medien steuern, wurde auch von Franziskus bemerkt und als Hindernis im Bauen eines stimmigen Bildes der Welt angesehen. Die besprochenen Päpste wiesen auf die Notwendigkeit der christlichen Formation sowohl der Sender als auch der Empfänger auf. Sie glaubten, sie sind zur Evangelisierung und einer gewissenhaften ekklesischen Information zu nutzen. Neue Medien sollen ein gegenwärtiger Areopag werden, ein Ort des Treffens, in

${ }^{16}$ Siehe Paul VI., Orędzie na 1. Światowy Dzień Środków Społecznego Przekazu „Środki społecznego przekazu ważnymi elementami cywilizacji", 24. Januar 1967.

${ }^{17}$ Siehe Johannes Paul II., ebenda.

${ }^{18}$ Vergl. M. Wrzos, Neue Missionsmedien in Polen vor dem Hintergrund der Papstbotschaften zum Welttag der Massenmedien, in: „Studia Misjologiczne” 1 (8) 2018, S. 165-198. 
der Dialogkultur, auch für Menschen unterschiedlicher Religionen und Kulturen. Sie sind eine Chance für die Vertiefung der Bindungen, jedoch auch eine Gefahr.

Die Anwesenheit der Gemeinschaft der Kirche und ihrer Institution im virtuellen Raum, insbesondere unter den säkularen Sendern, ist notwendig und sogar unerlässlich, um die Evangelisierung mithilfe aller verfügbaren Werkzeuge zu führen. Ihre sachkundige Handhabung kann nicht nur das religiöse Bewusstsein der Internetnutzer ändern, sondern auch die christliche Einstellung im realen Leben gestalten. Internet kann als vielschichtiger Raum sowohl ein Ort des Gedankenaustauschs, der Evangelisierung, als auch ein Werkzeug der Verkündung von Evangelium werden. J. Kloch erhebt eine Forderung, das Internet auch als Werkzeug der Evangelisierung zu nutzen. Er glaubt, die Kirche, ihre partikulären Gemeinschaften und Institutionen sollen dieses Werkzeug zur Verkündung der Frohen Botschaft (Evangelisierung, Katechesen, Information), zum Heiligen (Bibel,

\section{Obwohl die Reichweite der christlichen Internetportale nicht groß ist, wird die Kirchenlehre darin dargestellt. In den Laienportalen sind jedoch die Kirche und die Kirchenlehre in begrenztem Umfang anwesend.}

Gebet, Exerzitien, Informationen über Pilgerreisen), zum Verbreiten der Wohltätigkeit (Sozialhilfe, Freiwilligendienst, Zusammenarbeit, Bilden der Gemeinschaft um die Initiative) und zum Lehren (theologische Reflexion, Bildung der ekklesischen Gemeinschaft) ${ }^{19}$.

Obwohl die Reichweite der christlichen Internetportale nicht groß ist, wird die Kirchenlehre darin dargestellt. In den Laienportalen sind jedoch die Kirche und die Kirchenlehre in begrenztem Umfang anwesend. Die Anzahl der veröffentlichten Mitteilungen betreffend die päpstlichen Pilgerreisen sinkt. Die meisten Nachrichten in den analysierten Portalen (www.onet.pl; www.wp.pl; www.interia.pl; www.gazeta.pl; www.o2.pl; www.fakt.pl) wurden während der jeweiligen

${ }^{19}$ Siehe J. Kloch, Kościół w Polsce wobec Web 2.0, Kielce 2013, S. 209-278. 
päpstlichen Pilgerreise und die übrigen bis 10 Tage davor und maximal 3 Tage danach, obwohl in einigen Fällen es der letzte Tag der Pilgerreise war, veröffentlicht (der Zeitunterschied bewirkte, dass die Nachrichten offiziell am nächsten Tag veröffentlicht wurden). Die die jeweilige Pilgerreise betreffenden Informationen „lebten“ somit ein paar Tage in den am meisten meinungsbildenden Portalen. Es gab sie im Durchschnitt zirka 40 je apostolischer Besuch $(43,25)$ in den sechs analysierten Portalen. Darunter gab es auch solche, z. B. betreffend die Schweiz oder die baltischen Länder, wo die Benachrichtigung über die päpstliche Pilgerreise sehr gering war bzw. mit der Beendigung der Pilgerreise zusammenfiel. Es wurde noch kein Werkzeug bearbeitet, das prüfen lässt, wie lange die jeweilige Nachricht auf der Hauptseite bleibt. Möglicherweise waren es ephemere Nachrichten. Am meisten wurden kopierte Agenturnachrichten ohne Kommentar veröffentlicht. Eine Ausnahme waren hier die Portale, die mit den katholischen Redaktionen eng zusammenarbeiten. Die engste Zusammenarbeit nahm der Portal www.onet. pl mit "Tygodnik Powszechny“ auf. Das Portal www.interia.pl nutze sporadisch die Texte von „Przewodnik Katolicki“. In diesen zwei Portalen kann man die meisten theologische, obwohl einzelne Besprechungen und breitere Übermittlung der päpstlichen Lehre sehen. Es scheint, es sei der richtige Weg, damit so viele wie möglich mit dem Leben der Kirche verbundenen Informationen in den Internetmedien veröffentlicht werden und damit sie zuverlässig dargestellt werden. Um zur Veröffentlichung solcher Inhalte in diesen Portalen zu führen, müssen sie den Redaktionen zur Verfügung gestellt werden. Eine gute Lösung wäre es auch, dass die Redaktionen eine enge Zusammenarbeit mit bestimmtem katholischen Medium bzw. einem Theologen - Journalisten gewährleistet hätten.

Es wäre nötig, dass die zentralen Kircheninstitutionen wie Nachrichtenbüro der Polnischen Bischofskonferenz oder der Pressesprecher der Apostolischen Nuntiatur eine Gruppe Menschen bilden würden, die sich mehr um die Anwesenheit der Kirche in den Medien durch Erstellung von die päpstlichen Pilgerreisen vorbereitenden bzw. zusammenfassenden Texten kümmern möchten. Auf ihren Seiten werden derartige Besprechungen üblicherweise nicht veröffentlicht. Wichtig, dass die Texte kommunikativ für den Empfänger sind und dass sie gemäß den Regeln des Internetjournalismus vorbereitet werden. Es können Laienfreiwilligen tun, den es lohnt sich, zu vertrauen und diesen Teil der Funktion der Kirch als den zu überlassen, die besser mit diesem Kommunikationswerkzeug umgehen können. Die Redaktionen, die fertige manchmal über interessante Elemente der 
Pilgerreise Mitteilungen oder Besprechungen erhalten, werden ein Werkzeug haben sie zu nutzen. Ein Teil davon nutzt keine Informationen von KAI aufgrund der Gebührenpflicht.

Gemäß der Forderung von J. Kloch ist eine breitere Anwesenheit der Kirche in den Internet- und Laienmedien möglich. Durch die Zusammenarbeit mit Internetmedien, die sich dafür interessieren, ist ihre noch breitere Nutzung möglich, insbesondere zur Evangelisierung, zu Katechesen, zur Information, zur Verkündung der ekklesischen Lehre zum jeweiligen Thema oder zum Bilden einer Gemeinschaft der Menschen, die sich an einer Initiative beteiligen möchten. Eine Voraussetzung scheint die Zusammenarbeit der Kirche mit diesen Medien und das Wirken der Menschen, die neue Medien nutzen können, zu sein. Eine deutliche engere Zusammenarbeit der Kirche mit den säkularen Medien ist somit notwendig. Ihre große Reichweite und Wirkungsbereich sollte dafür verwendet werden,

\section{Eine deutlich engere Zusammenarbeit der Kirche mit den säkularen Medien ist notwendig. Ihre große Reichweite und Wirkungsbereich sollte dafür verwendet werden, über Ereignisse aus dem Kirchenleben besser und mehr zu informieren.}

über Ereignisse aus dem Kirchenleben besser und mehr zu informieren. Die Pilgerreisen des Papstes, seine Lehre, Missionen, Engagement für ausgeschiedene Personen, Tätigkeit der Jugend sind Themen, die ein positives Image der Kirche in neuen Medien bilden sollten.

Es scheint eine Änderung der journalistischen Narration auf die nicht direkt mit dem theologisch- seelsorgerischen Thema der päpstlichen Besuche verbundenen Fragen bemerkbar zu sein, was aufgrund der Natur dieses Kommunikationswerkzeugs nicht wundert. Die Redakteure weisen auf die sexuellen Missbräuche von Minderjährigen, die Seelsorge von homosexuellen Personen oder unerwartete Ereignisse während der Besuche wie zufälliger Schlag des Papstes, Sturz der Polizisten aus dem Pferd und die ihr erteilte Hilfe vom Bischof von Rom hin. Papst Franziskus gewinnt auch durch bildliche Sprache und den Seelsorgestil wie z. B. 
Trauung der Stewards im Flugzeug die Aufmerksamkeit der sozialen Kommunikationsmittel. Es ist wünschenswert, dass derartige Narration die Grundlage für weitere vertiefte Evangelisierugs- und theologische Überlieferung wird, was in der medialen Strategie der Kirche zu berücksichtigen wäre.

Die Entwicklung der Technik bewirkt, dass die menschlichen Gewohnheiten sich schnell ändern. Mit dem Auftreten von Neuheiten gehen unsere Gewohnheiten auf ganz anderes Gleis. Dies gilt auch für den Zugang zur Information. Zuerst erschienen unter den sozialen Kommunikationsmitteln Zeitschriften, Radio, Fernsehen und heute ist das Internet sowie Medien, die die Technologie der Gedankenübertragung nutzen, das am meisten verbreitete Medium, das von rund $80 \%$ der polnischen Gesellschaft genutzt wird. Junge Leute lesen sporadisch Zeitschriften, hören Radio, am häufigsten sind sie stets „online“ anhand der Computer und der Mobilgeräte (Telefone, Tablets, Uhren, Handschuhe usw.). Neben den Internetmedien wie Webseiten und Internetportalen, sozialen Medien (Facebook, Twitter, Google+, Instagram oder Pinterest) spielen derzeit die größte Rolle die beliebtesten publizistischen Portale. Manche von ihnen erreichen mehr als 12,2 Mio. Leser monatlich, die das Portal auch ein paar Mal täglich lesen (www.wp.pl). In ihren Ressourcen, wie es scheint, sollen sich mit der Kirche, darunter auch mit den päpstlichen Pilgerreisen zusammenhängende Informationen befinden.

Aus den durchgeführten Forschungen geht es hervor, dass die päpstlichen Pilgerreisen kleines Interesse der analysierten Portale genossen. Über die vier päpstlichen Pilgerreisen (15.-21. Januar - Chile, Peru; 21. Juni - die Schweiz; 25.-26. August - Irland; 22.-25. September - Litauen, Lettland, Estland) wurden auf allen Portalen insgesamt 174 Informationen. somit 43,25 im Durchschnitt veröffentlicht. Am häufigsten waren es nach folgenden Agenturen veröffentlichte Nachrichten: der Katholischen Informationsagentur (KAI), der Polnischen Nachrichtenagentur (PAP), der Rundfunkinformationsagentur (RAI) und Radio Vatikan (RV). Ihre Anzahl beträgt 148 von 174, was 85,1\% der gesamten oft in verschiedenen Diensten duplizierten Informationen darstellt. Unter ihnen treten auch Bilder auf. Die Zeit der Veröffentlichung entsprach meistens der Zeit der apostolischen Reise selbst. Manchmal wurde sie durch Ankündigungen bzw. Zusammenfassungen eingeleitet, am häufigsten wurden sie jedoch nicht früher als 7 Tage veröffentlicht. Die sogenannte Lebensdauer einer päpstlichen Pilgerreise im Portal betrug durchschnittlich 7 Tage (so lange erschienen die Nachrichten zu diesem Thema, obwohl sie auf der Hauptseite nur für 2-3 Stunden anwesend 
waren) unter der Voraussetzung, dass die Pilgerreise überhaupt von der Redaktion des jeweiligen Portals bemerkt wurde. Der Anteil an negativen, positiven und neutralen Nachrichten war vergleichbar und unter den Portalen ist keines bemerkbar, das sich durch in Frage stellen der ekklesischen Tätigkeit auszeichnen würde. In der Regel konzentrierte man sich nicht auf die Inhalte der päpstlichen Botschaft, sondern auf die sexuellen Missbräuche von Minderjährigen, die Seelsorge von homosexuellen Personen oder unerwartete Ereignisse während der Besuche wie zufälliger Schlag des Papstes, Sturz der Polizisten aus dem Pferd und die ihr erteilte Hilfe vom Bischof von Rom.

Es scheint, dass die Zusammenarbeit mit den Internetmedien enger sein sollte. Es wäre vor allem für die Rezipienten von Vorteil, die ein breiteres Bild dessen erhalten könnten, wie die kirchliche Realität wirkt. Die zentralen Institutionen der Kirche hätten bei der Vorbereitung der Informationen über die Tätigkeit der Kirche, und früher bei Erarbeitung der medialen Strategie, bei der Zusammenarbeit mit den Laienredaktionen die Chance, ein positives Image zu kreieren sowie mehr Informationen oder theologischen Kommentaren zu veröffentlichen. Es ist wichtig, dass die Theologen, darunter Geistlichen, vorbereitet sind, sich der zu einem solchen Journalismus notwendigen Werkzeuge zu bedienen. Die Pilgerreisen des Papstes, insbesondere die Missionsreisen, seine Lehre, Missionen, Engagement für ausgeschiedene Personen, Tätigkeit der Jugend sind Themen, die ein positives Image der Kirche in den Internetmedien bilden sollten.

Als Zusammenfassung und Antwort auf die Forschungshypothesen scheint es, dass die erste: „Die Medien in Polen informieren sachgemäß über die Auslandspilgerreisen von Papst Franziskus (quantitativ und qualitativ)“ sei unbestätigt. Die zweite: „Die Vorbereitung der Geistlichen zur Benutzung neuer Medien und zur Benachrichtigung über die mit der Kirche verbundenen Fragen ist sachgemäß“ ist unbestätigt; und die dritte: „Die Anzahl der Informationen und die Benachrichtigungsart über die Auslandspilgerreisen ist ungenügend“ sei bestätigt.

\section{BIBLIOGRAFIE}

\section{A. Analysierte Dienste.}

Http://www.fakt.pl, [Jahr 2018].

Http://www.gazeta.pl, [Jahr 2018].

Http://www.interia.pl, [Jahr 2018]. 
Http://www.o2.pl, [Jahr 2018].

Http://www.onet.pl, [Jahr 2018].

Http://www.wp.pl, [Jahr 2018].

\section{B. Sonstige Publikationen}

Benedikt XVI., Orędzie na 43. Światowy Dzień Środków Społecznego Przekazu. Nowe technologie, nowe relacje. Trzeba rozpowszechniać kulturę szacunku, dialogu i przyjaźni, 24. Januar 2009.

E. Chudziński [Red.], Słownik wiedzy o mediach, Warszawa - Bielsko-Biała 2007

Franziskus, Orędzie na 50. Światowy Dzień Środków Społecznego Przekazu Komunikacja i Miłosierdzie - owocne spotkanie, 24. Januar 2016.

Franziskus, Orędzie na 52. Światowy Dzień Środków Społecznego Przekazu «Prawda was wyzwoli» (J 8, 32). Fake news a dziennikarstwo pokoju“, 24. Januar 2018.

Franziskus, Orędzie na 54. Światowy Dzień Środków Społecznego Przekazu "Abyś opowiadał dzieciom Twoim i wnukom» (Wj 10, 2). Życie tworzy historię", 24. Januar 2020.

Goban-Klas T., Media i komunikowanie masowe. Teorie i analizy prasy, radia, telewizji i Internetu, Warszawa 1999.

Hofman I., Paradygmaty nowej dyscypliny, in: „Studia Medioznawcze” 2019, (79) 4, S. 308-317.

J. Kloch, Kościół w Polsce wobec Web 2.0, Kielce 2013, S. 209-278.

Johannes Paul II., Orędzie na 24. Światowy Dzień Środków Społecznego Przekazu, Misja Kościoła w erze komputerów, 24. Januar 1990.

Kloch J., Kościół w Polsce wobec Web 2.0, Kielce 2013.

Krzysztofek K., Status mediów cyfrowych: stare i nowe paradygmaty, in: „Global Media Journal - Polish Edition" 2006, (1) 1, S. 14.

Levinson P., Nowe nowe media, Kraków 2010.

Manovich L., Język nowych mediów, Warszawa 2006.

Manovich L., New Media From Borges to HTML, Massachusetts 2003.

Nieć M., Komunikowanie społeczne i media, Warszawa 2010.

Paul VI., Orędzie na 1. Światowy Dzień Środków Społecznego Przekazu „Środki społecznego przekazu ważnymi elementami cywilizacji”, 24. Januar 1967.

Roman K., Najnowsze nowe media i stare nowe media. Spór o definicję nowych mediów, in: „Dyskurs” 2016, (22) 2, S. 20-39.

Szpunar M., Czym sq nowe media - próba konceptualizacji, in: „Studia medioznawcze” 2008, (35) 4, S. 32.

Szpunar M., Imperializm kulturowy Internetu, Kraków 2017, S. 3-134.

Szpunar M., W stronę nowych mediów, Toruń 2010.

Wrzos M., Neue Missionsmedien in Polen vor dem Hintergrund der Papstbotschaften zum Welttag der Massenmedien, in: „Studia Misjologiczne” 1 (8) 2018, S. 165-198. 


\section{Biogramm}

Marcin Wrzos OMI (geb. 1977), Priester, Missionar Oblate der Makellosen Jungfrau Maria; Doktor der Theologie im Fachgebiet Missionswissenschaft und Theologie der sozialen Kommunikationsmittel UKSW (2013), er absolvierte das Studium in politischen Wissenschaften und Journalismus UAM (2008), Polonistik UJ (2016) sowie Schutz personenbezogenen Daten UKSW (2018). Autor von Artikeln über Missionen in den sozialen Kommunikationsmitteln sowie über Nutzung der sozialen Kommunikationsmittel in Missionen. Er forscht die Anwesenheit der Kirche im Internet. Autor von vier Buchpublikationen: „Polskie czasopisma misyjne po II wojnie światowej. Studium misjologicznoprasoznawcze“ „Bibliografia polskich czasopism misyjnych. Lata 1945-2013“, „Oblates missionary press in Europe“ (Redakteur) und "Główne idee teologiczne, historia i funkcje oblackiego czasopiśmiennictwa misyjnego w Polsce (1926-2016)“ sowie von mehr als zehn wissenschaftlichen Artikeln. Ei ist freier Mitarbeiter der Fakultäten für Theologie der Universitäten UAM und USz. Er leitet die Veröffentlichung von „Misyjne Drogi“ und das Internetportal misyjne.pl.

ORCID: 0000-0003-3513-0158 